This is the author's final, peer-reviewed manuscript as accepted for publication. The publisher-formatted version may be available through the publisher's web site or your institution's library.

\title{
Neuropathology and diagnostics in food animals
}

Jerome C. Nietfeld

\section{How to cite this manuscript}

If you make reference to this version of the manuscript, use the following information:

Nietfeld, J. C. (2012). Neuropathology and diagnostics in food animals. Retrieved from http://krex.ksu.edu

\section{Published Version Information}

Citation: Nietfeld, J. C. (2012). Neuropathology and diagnostics in food animals. Veterinary Clinics of North America-Food Animal Practice, 28(3), 515-534.

Copyright: @ 2012 Elsevier Inc.

Digital Object Identifier (DOI): doi:10.1016/j.cvfa.2012.07.008

Publisher's Link:

http://www.sciencedirect.com/science/article/pii/S074907201200059X

This item was retrieved from the K-State Research Exchange (K-REx), the institutional repository of Kansas State University. K-REx is available at http://krex.ksu.edu 


\title{
Neuropathology and Diagnostics in Food Animals
}

\author{
Jerome C. Nietfeld, DVM, PhD \\ Department of Diagnostic Medicine/Pathobiology, Mosier Hall, \\ College of Veterinary Medicine \\ Kansas State University \\ Manhattan, KS 66506
}

Phone: $785-532-4460$

Fax: 785-562-4481

Email: nietfeld@vet.k-state.edu

The author has nothing to disclose.

Key words: Neuropathology, diagnostics, cattle, sheep, pigs, food animals 
Diseases of the central nervous system are relatively common in food animals. Potential causes include infectious agents, nutritional deficiencies, metabolic disorders, genetic defects, toxins, and idiopathic causes. Food animals are frequently raised in large groups, there is often human and animal traffic between groups, and large numbers of animals are often fed the same ration. This makes it important to obtain an accurate etiological diagnosis as soon as possible so that treatment can be initiated and to limit the spread of infectious agents and toxins.

In all disease situations, an antemortem diagnosis is preferable to a postmortem one because it allows for possible treatment of affected individuals, but that is not always possible and determining the correct etiologic diagnosis often depends on a thorough postmortem examination and collection of samples. Critical components for obtaining a successful diagnosis are as complete a history as possible, a thorough examination of affected and unaffected animals and their surroundings, a thorough necropsy and collection of the appropriate diagnostic samples, and accurate interpretation of the findings. The goals of this article are to review some of the steps and procedures necessary to collect the necessary information, to briefly describe a few techniques for examination of the central nervous system, and to review the gross pathology of conditions likely to be encountered in a food animal practice.

\section{Signalment and History}

Knowing the age, sex, breed, intended use, and management of animals provides a lot of valuable information because the differentials for neurological diseases for neonates, juveniles and adults are usually different. Similarly, the differentials for cows at pasture are often different than those for dairy cattle. A three day old calf is much more likely to have Escherichia coli meningitis than an adult dairy cow, while a dairy cow being fed corn silage is more likely to 
have listeriosis. Similarly, calves in a feedlot are more likely to develop polioencephalomalacia than those on pasture.

As complete a history as possible and a thorough description of the problem as seen by the animals' caretaker are important. How long has the problem been going on? What are the major clinical signs? Are the clinical signs mild, severe, or intermediate when first noticed? Are animals found unexpectedly dead? Have any been treated? Do they improve with time or treatment? How large is the group, what is the morbidity and mortality? Is the situation improving, static, or worsening? Do affected animals continue to eat and drink? These and other questions will often provide valuable clues as to whether the problem is neurologic or referable to another system and give insight into potential causes. For instance, knowing that a young goat with severe paresis or paralysis of the rear legs (Fig. 1) has been steadily becoming more ataxic and weaker for several weeks leads one to suspect caprine arthritis-encephalitis virus infection, while spinal trauma is more likely if the goat was normal yesterday. Knowing that calves with acute neurologic symptoms that include blindness and are suspected of having polioencephalomalacia have not responded to thiamine treatment should make one suspect lead poisoning.

\section{Examination of Living Animals}

A neurologic exam combined with a thorough history will usually allow the clinician to determine if a problem is due to disease of the CNS or another organ system and it will help localize the problem. Although many procedures used to examine small animals and horses are often not possible with food animals, protocols for safe examination of food animals have been described. ${ }^{1,2}$ In some cases the diagnosis will be made on the basis of the clinical exam and 
history. Tetanus is a good example. Diagnostic tests to identify tetanus toxin are rarely available, isolation is usually not attempted or is negative, and there are no pathologic lesions. Consequently, diagnosis is almost always based on clinical signs that include stiffness, tonic spasms, and hyperesthesia that progress to lateral recumbency and generalized tetanic spasms with the head thrown back and the limbs rigid (Fig. 2A). If the animals have visible wounds or the history indicates that they had surgery or gave birth within the past few weeks, one can feel even more certain of the diagnosis. However, it is important to rule out other possible diseases, such as bacterial meningitis which can clinically resemble tetanus and can also follow surgical procedures and wounds (Fig. 2B).

As part of the examination, collect and save serum and whole blood. They may not be needed, but in some cases blood and/or serum will be useful or necessary for making a diagnosis. For instance, cerebral hypoxia caused by anaplasmosis (or other causes of severe acute anemia) and hypocalcemia can cause aggression in cows and the diagnosis of both is difficult without serum or blood. Hepatic encephalopathy, hypomagnesemic tetany in ruminants, and hypoglycemia in neonatal pigs are additional examples of diseases with neurologic signs where serum is helpful in making a diagnosis. Lead poisoning, sodium toxicity due to water deprivation, and polioencephalomalacia of ruminants are clinically similar and are characterized by signs of cerebral disease. Lead poisoning can be diagnosed by determining the concentration of lead in whole blood and sodium toxicity can often be diagnosed by determination of serum sodium. Diagnosis of polioencephalomalacia requires examination of the brain and elimination of the other two conditions. Selenium toxicity in pigs can cause necrosis of spinal cord grey matter resulting in paresis and paralysis and can be diagnosed by determination of blood selenium. Whole blood as well as hair and skin are often used to identify heterozygous and 
homozygous carriers of many inherited diseases, such as $\alpha$ - and $\beta$-mannosidosis in various breeds of cattle and Nubian goats, and arthrogryposis multiplex in Angus calves.

Cerebrospinal fluid (CSF) can provide useful information, and techniques for safe collection from the lumbosacral space, processing, examination, and interpretation of the results have been described. ${ }^{3}$ Cerebrospinal fluid analysis is most useful for diagnosis of infectious diseases as opposed to noninfectious toxic, metabolic, and degenerative diseases in which the CSF characteristics are often normal. ${ }^{3,4}$ Acute bacterial infections, such as neonatal meningitis and thrombotic meningoencephalitis (TME) caused by Histophilus somni (Haemophilus somnus) are typically accompanied by a neutrophilic pleocytosis, ${ }^{3,4}$ and often an etiologic diagnosis can be made by bacterial culture. Chronic bacterial diseases, such as listeriosis and sometimes abscesses, and viral diseases tend to be accompanied by mononuclear pleocytosis. ${ }^{4}$ The usual recommendation is that cytologic examination of CSF samples should be done within two hours of collection. ${ }^{3}$ However, a recent study found no significant differences between total and differential cell counts in CSF samples from calves using split samples examined within 1 hour and 24 hours after collection when the 24 hour samples were stored at $4{ }^{\circ} \mathrm{C}$ after adding $11 \%$ autologous serum. ${ }^{5}$

\section{Postmortem Examination}

\section{Examine and Collect Samples from Entire Animal}

In many cases animals are found dead, they die despite treatment, they are euthanized for humane reasons, or it is more economical to euthanize them, and it is necessary to perform a necropsy and collect samples in order to support or make a diagnosis. Multiple reviews for performing food animal necropsies have been published and while the methods differ all 
accomplish the same goals. ${ }^{6-11}$ Even in cases where all clinical signs point to neurologic disease, it is important to thoroughly examine the entire carcass because there are a number of neurologic diseases that cannot be diagnosed by examination and/or testing CNS samples. Sample collection should be done with the idea that it is better to save a sample and not need it then to later wish we had saved it. Table 1 lists infectious diseases, metabolic diseases, and common toxicities that often are accompanied by neurologic symptoms. Many require other than CNS samples to make a correct diagnosis.

Cerebrospinal fluid can often be collected while disarticulating the head at the atlantooccipital joint. ${ }^{10}$ Incise the tissues covering the ventral surface of the joint, including the atlanto-occipital membrane, and insert a needle attached to a syringe through the dura mater until hitting bone. Withdraw the needle slightly and aspirate (Fig. 3). If the needle is inserted off midline the likelihood of aspirating blood is decreased. The CSF should be clear, and cloudiness suggests bacterial infection. Blood could be from antemortem hemorrhage, but is more likely from puncturing a vein during collection. In suspected cases of bacterial meningitis, CSF is an excellent sample for bacterial culture.

Always remove and save unfixed and fixed tonsils of pigs because they are a preferred sample for many diseases, such as pseudorabies, Teschovirus (Enterovirus), classical swine fever, African swine fever, porcine reproductive and respiratory syndrome virus, and porcine circovirus type 2. Similarly, remove and save the retropharyngeal lymph nodes of sheep, goats, and cervids, because they and the obex are used for diagnosis of scrapie in sheep and goats, and chronic wasting disease in cervids (Fig. 4).

If hypomagnesemic tetany is a possible cause of death, remove the eyes and either collect the vitreous humor or save the entire eye for magnesium analysis. Concentrations of $\mathrm{Mg}$ in 
serum, CSF, aqueous humor and vitreous humor are related in living cattle, but after death $\mathrm{Mg}$ is released from cells and the concentration in serum rises rapidly, and the concentration is not stable in CSF or aqueous humor, but it is stable in the vitreous humor. ${ }^{12,13}$ Magnesium concentrations $\leq 0.55 \mathrm{mmol} / 1(1.3 \mathrm{mg} / \mathrm{dl})$ in the vitreous humor of adult cattle are diagnostic of hypomagnesemia for up to 48 hours after death. ${ }^{12,13}$ Similarly, $\mathrm{Mg}$ concentrations $\leq 0.65$ $\mathrm{mmol} / \mathrm{L}(1.6 \mathrm{mg} / \mathrm{dl})$ in the vitreous humor of adult sheep are diagnostic for up to 24 hours. ${ }^{13}$ Ocular fluid is also often used to diagnose nitrate toxicity.

\section{Removal of the Brain and Collection of Samples for Rabies and TSEs}

With only a little practice brains can be removed quickly and safely. Consequently, it is common for veterinarians to remove and submit brains from food animals. Probably the simplest method is to cut the skull lengthwise on the midline with a saw and remove the brain from the respective halves (Fig. 5). The brain can also be removed intact with a hatchet, axe, cleaver, chisel and mallet, or hand saw. ${ }^{6-11}$ While removing the brain it is important to closely examine it, the bones of the calvarium, and the meninges for fractures, hemorrhages, tumors and other space occupying lesions, purulent exudate, and other abnormalities.

If rabies is a possibility, it is critical that the proper samples be collected and properly submitted to the laboratory. In the past, a common recommendation was to split the brain lengthwise and submit half fresh and half in $10 \%$ buffered formalin. ${ }^{14}$ This is no longer acceptable. The CDC requires that a complete cross section of brain stem and either the cerebellum or the hippocampuses, with the cerebellum preferred, be tested for a brain to be

reported as negative,. ${ }^{15}$ The preferred sample is a transverse section through the cerebellum and the underlying brainstem submitted unfixed, either frozen or unfrozen (Fig 6). If the brain is 
split lengthwise submit sections from both halves of the brainstem and cerebellum. Remove the brainstem section for rabies anterior to the obex and save the obex from ruminants in case there is a need to test for a transmissible spongiform encephalopathy (TSE)—scrapie, chronic wasting disease, or bovine spongiform encephalopathy (Fig. 6). After saving samples for rabies and TSE tests, one can split the brain lengthwise and fix half and keep half fresh.

\section{Removal and examination of the Spinal Cord}

The spinal cord is more difficult and time consuming to examine and remove.

Consequently, it is not examined in many cases where it would be helpful or necessary to make a definitive diagnosis. However, realistically it is not necessary to remove the spinal cord in all cases where there is evidence of spinal cord involvement. If one finds evidence of lymphoma in lymph nodes and organs of a down, alert cow and concludes that the cow is recumbent because of lymphoma involving the spinal canal without opening the canal, they will rarely be wrong. Close examination of the outer surfaces of vertebral bodies will often reveal fractures or abscesses that are the cause of paresis and paralysis making cord removal unnecessary (Fig. 7).

In cases where there is diffuse involvement of the CNS, such as viral or bacterial infections, the diagnosis can usually be made by examination of only brain or brain plus sections of the spinal cord. For example, the tonsil, brain, and trigeminal ganglia are the specimens of choice for identification of pseudorabies virus in pigs. In other species, such as cattle, infection is often by the oral route and the virus follows autonomic nerves from the intestines to the spinal cord and from the cord to the brain. Sometimes animals die before detectable virus reaches the brain, and for animals other than pigs the specimens of choice are the most distal portion of the brain stem and spinal cord. In this type of case, a few pieces of spinal cord are as good as the 
entire cord. One can make transverse cuts through the vertebral column and remove sections about two vertebrae in length (Fig. 8A). Swab the subdural space with a bacterial culturette and save for bacterial culture. Using a pair of thin scissors and a small tweezers cut the nerve rootlets and remove the pieces of cord (Fig. 8B).

In some cases the entire cord needs be removed in order to make the correct diagnosis. Removing the entire cord is more work than removing a few pieces, but it can be done in the field. In neonatal animals, especially pigs, sheep, and goats, the cord can be exposed by removing the dorsal arches with diagonal pliers purchased at the hardware store (Fig. 9). The cord of calves up to $150-200 \mathrm{~kg}$, juvenile goats and sheep, and nursery/finishing pigs can be exposed with a hand saw by laying the animal on its side, removing the limbs and ribs from the up side, and cutting parallel to the dorsal processes just off the midline so that the saw opens the spinal canal, but does not cut into the cord (If you do cut the cord in a few places, it will still be useful) (Fig. 10). The bones of young animals are relatively soft and with a good hand saw one can expose the lumbar through thoracic cord of young calves in only a few minutes. Opening the spinal canal of the cervical vertebrae is a little more difficult, but it also can be accomplished in just a few minutes. This technique is especially helpful in examining young animals for things like vertebral fractures, abscesses, meningitis, and vertebral malformations. Opening the spinal canal of larger animals such as juvenile and adult cattle and adult swine can be accomplished with an axe by chopping away the lateral portions of the vertebrae (Fig. 11). It is messy and considerable work, but it takes little if any longer to expose the cord with an axe than by cutting the vertebral column into sections and exposing the cord with a band saw. Once the cord is exposed, examine the vertebrae and intervertebral disks for abnormalities and remove the cord by grasping the dura mater with a forceps and cutting the nerve rootlets. Open the dura with a 
scissors, swab the subdural space, remove a few pieces of fresh cord for bacterial and viral testing, and fix the remainder in formalin.

\section{Gross Pathology of the Brain and Spinal Cord}

\section{Meningitis, encephalitis, and meningoencephalitis}

Cloudiness and purulent exudates on the meningeal surfaces are indicative of bacterial meningitis, which is more likely in young animals than adults (Fig. 12). Bacterial meningitis is a systemic disease and finding fibrinopurulent arthritis and polyserositis in young animal should alert one to the possibility of meningitis. Hemorrhages on the outer or cut surfaces of cattle brains, especially feedlot cattle, are indicative of thrombotic meningoencephalitis (thromboembolic meningoencephalits) caused by Histophilus somni (Fig. 13). Cloudy joint fluid and CSF, and hemorrhages in the heart of feedlot cattle suggest that $H$. somni infection of the brain is likely (Fig. 14). Swollen thin walled lateral ventricles and swellings and soft spots in other areas of the brain can represent an abscess, hemorrhage, or tumor (Fig. 15).

Listeriosis of ruminants affects the brainstem, but is usually not accompanied by macroscopic lesions. Bacterial isolation is often unsuccessful and the most common method of diagnosis by identification of characteristic microabscesses in histologic sections of brainstem. In my experience, identification of Listeria spp. by immunohistochemical staining of formalinfixed brain is more often successful than bacterial culture. The two most important differentials for listeriosis are otitis media/interna and a brainstem abscess, which can be eliminated at necropsy. Also, animals with otitis are typically alert and do not have nystagmus. ${ }^{2,16}$ Enterotoxemia (overeating disease, pulpy kidney disease) caused by Clostridium perfringens type $\mathrm{D}$ in young lambs and calves is sometimes accompanied by neurologic signs 
that can include ataxia, head pressing, blindness, and convulsions. In subacute cases there often are bilaterally symmetrical areas of hemorrhage and/or yellow discoloration in the midbrain and brain stem, which represent necrosis caused by toxin absorbed from the intestines. ${ }^{17,18}$ In many cases, the necrosis is only visible microscopically and it is only pathologic change that is considered diagnostic for enterotoxemia. Diagnosis can also be by identification of epsilon toxin in the intestinal contents or isolation of $C l$. perfringens type $\mathrm{D}$ from the intestines.

Viral infections typically cause nonsuppurative encephalitis or encephalomyelitis, but gross pathology is rare. Both formalin-fixed and unfixed brain, spinal cord, and other tissues are important for diagnosis. Even in cases where the virus is identified in neurologic tissues, it is helpful to examine the CNS for inflammation.

\section{Hydrocephalus and hydrancephaly}

Hydrocephalus and hydrancephaly are relatively common, especially in neonatal food animals. Hydrocephalus is an increased volume of CSF in the cranial cavity because of restriction of circulation of the CSF or CSF filling spaces normally occupied by tissue that failed to develop. In food animals, only internal hydrocephalus with accumulation of CSF in the ventricles is common and it is usually secondary to defects that restrict normal flow of CSF (Figs. 5 and 16). ${ }^{17}$ Hydranencephaly is due to necrosis of developing cerebral tissue with accumulation of CSF in the resulting cavities (Fig. 17). It can vary from almost complete destruction of the cerebrum leaving only a CSF-filled sac (Fig. 17A) to small fluid-filled holes in the cerebrum, referred to as porencephaly (Fig. 17B).

Hydranencephaly is most commonly the result of in utero viral infection. In North America, viral causes include Cache Valley and Border disease (BD) viruses in sheep, 
bluetongue virus in sheep and cattle, and bovine viral diarrhea (BVD) virus in calves. ${ }^{14,17,18}$ Worldwide, other viral causes of hydranencephaly include Akabane, Rift Valley fever, and Wesselsbron viruses in calves and sheep and Chuzan virus in calves. ${ }^{14,17,18}$ Since November, 2011 a virus provisionally named Schmallenberg virus in the genus Orthobunyavirus, which includes Cache Valley and Akabane viruses, has been associated with outbreaks of hydrancepahly and scoliosis in sheep, goats, and cattle in Germany, Belgium and the Netherlands. ${ }^{19}$ Diagnosis of in utero viral infection is by identification of the virus in tissues from newborn or aborted animals or by detection of virus-specific antibody in serum obtained prior to ingestion of colostrum. In utero copper deficiency (congenital swayback) is a noninfectious cause of hydrancephaly in lambs and kids..$^{17,18,20}$

Congenital hydrocephalus occurs in all food animal species and can be inherited as an autosomal recessive defect in multiple breeds of calves and possibly pigs. ${ }^{17,18,20}$ Other causes of congenital hydrocephalus include the viral causes of hydranencephaly, ingestion of Veratrum californicum by pregnant sheep and cattle, and vitamin A deficiency in cattle because of defective absorption of CSF by the arachnoid..$^{17,18,20,21}$ Postnatal hydrocephalus can result from vitamin A deficiency in cattle and CNS inflammation in all species. ${ }^{17}$ Vitamin A deficiency in fetal and growing animals, especially calves and piglets, also impairs growth of membranous bones that can result in compression of the brain and optic nerves leading to stillbirths, blindness, ataxia, and seizures. ${ }^{21,22}$ At necropsy the optic canal is narrowed and there is compression of the brain with the cerebrum flattened and the cerebellum compressed and sometimes herniated into the foramen magnum (Fig. 18).

\section{Cerebellar Pathology}


Cerebellar hypoplasia is the failure of the cerebellum to develop fully (Fig. 19). The clinical signs are evident at birth, and it is a relatively common congenital anomaly that occurs in all animal species. The condition can be inherited in Hereford, Shorthorn, Aryshire, and Angus calves and occurs in piglets whose dams were treated during pregnancy with trichlorofon. ${ }^{17,18,23}$ Possibly the most common cause is viral infection at a stage of gestation when the cerebellum is developing rapidly. The most important causes are BVD virus in calves, BD virus in lambs, and classical swine fever (CSF) virus in piglets. ${ }^{17,18,20}$ Hypomyelination of the CNS frequently accompanies cerebellar hypoplasia caused by both in utero viral infection and exposure of pregnant sows to trichlorofon, and it is manifest as muscular tremors referred to as congenital tremors or myoclonia congenital. ${ }^{17,18,23}$ Congenital tremors in pigs can also be caused by pseudorabies virus and be inherited in a few breeds.

Cerebellar abiotrophy is the premature degeneration of the cerebellum and causes clinical signs of cerebellar disease in animals that were normal at birth. The cerebellum is normal size or slightly smaller than normal and diagnosis is by microscopic demonstration of excessive degeneration and loss of Purkinje cells and other cells in the cerebellum. Although toxic causes, such as in utero exposure to locoweed and organophosphates are sometimes suspected ${ }^{23}$ most cases are felt to be inherited. ${ }^{17,23}$

Generalized cerebral swelling due to edema can cause rearward displacement and coning of the cerebellum due to compression against the occipital bone (Fig. 20). Possible causes include bacterial encephalitis and/or meningitis, polioencephalomalacia, salt toxicity following water deprivation, and toxins such as lead and organomecurical compounds. ${ }^{17}$ Arnold-Chiari malformation is an uncommon congenital anomaly that results in displacement of the posterior cerebellum through the foramen magnum and is sometimes accompanied by spinal bifida ${ }^{18}$ 


\section{Laminar Cortical Necrosis of the Cerebrum (Polioencephalomalacia)}

Polioencephalomalacia of ruminants, sodium toxicity secondary to water deprivation in pigs, and lead poisoning in ruminants are characterized by similar clinical signs that include, but are not limited to, dullness, aimless wandering, head pressing, clonic convulsions, recumbency, and blindness. Pathologically, the lesions of polioencephalomalacia and water deprivation are cerebral edema and necrosis (malacia) of the outer lamina of grey matter of the cerebral cortex that sometimes can be seen as multifocal bands of yellow-brown discoloration. ${ }^{17,18}$ However, the malacic areas are usually difficult to identify with certainty, but when illuminated with a black light they glow and are easily recognized (Figs. 21A and 21B). Lead poisoning is sometimes stated to cause laminar necrosis, but the lesions are much more subtle and are usually not visible, even with a black light or microscopically. There is clinical evidence that sodium toxicity secondary to water deprivation can also cause laminar necrosis in ruminants, but it is

proven only in pigs. ${ }^{17}$ Sodium toxicity due to ingestion of excessive salt can cause clinical signs of neurologic disease, but it does not cause laminar necrosis and the reason for the neurologic signs is unknown. ${ }^{17}$

\section{Spinal bifida, Myelodysplasia and Arthrogryposis}

Myelodysplasia is abnormal development of the spinal cord and spinal bifida is incomplete closure of the dorsal arches of one or more vertebrae and usually affects the lumbosacral area (Figs. 16B and 22A and C). The two conditions can occur together or independent of one another and they are often accompanied by arthrogryposis (Fig. 22B) ${ }^{17}$ The arthrogryposis can involve one or two limbs or be generalized and often there is hypoplasia of 
muscles. Arthrogryposis can result from lack of movement in utero, but denervation is more common. ${ }^{17}$ The vertebral defect can be open so that the meninges are exposed (spinal bifida cystica) (Fig. 22A and C) or covered by skin so that the defect is not noticeable (spinal bifida occulta). In cases of spinal bifida occulta there usually is a small dimple at the location of the vertebral defect and radiographs are the best method for diagnosis.

In North America, congenital arthrogryposis and muscular hypoplasia, often accompanied by hydranecephaly and spinal cord hypoplasia, often occur in lambs infected in utero with Cache Valley virus (Figs. 9, 17 and 23). Akabane virus is another important cause of arthrogryposis and hydrancephaly in ruminants. ${ }^{17}$ Bluetongue, Border disease, and bovine viral diarrhea viruses are reported to cause arthrogryposis and hydrancephaly, but while brain malformations are relatively common, arthrogryposis is rare. Arthrogryposis can be inherited, ie. arthrogryposis multiplex of black Angus cattle, or be the result of ingestion of toxic plants by the mother during early gestation. Many cases are idiopathic.

\section{Other Causes of Spinal Cord Pathology}

The most common causes of pathology of the spinal cord are vertebral fractures, abscesses, infections, and lymphoma in cattle. Bacterial and viral meningitis/myelitis are often not grossly visible and diagnosis is dependent on histologic examination and identification of the causative agent. Fractures can be diagnosed at necropsy or radiographically. Although other types of neoplasia can occur, lymphoma of the spinal canal of cattle is the only type that is important. Lymphoma can closely resemble fat, but fat floats in formalin and lymphoma does not. Parelaphostrongylus tenuis is a nematode that normally resides in the subarachnoid space of white-tailed deer. Occasionally, the larvae migrate into the spinal cord of domestic ruminants, 
with South American camelids being the most susceptible. Sheep, goats, and especially cattle are relatively resistant and require large numbers of larvae for development of clinical signs, and cases are uncommon. Definitive diagnosis is by identification of the parasite in the spinal cord.

\section{Summary}

This article briefly reviews some of the clinical and necropsy procedures to follow while investigating cases of neurologic disease in food animals, such as obtaining a thorough history, examining affected live animals, their herd mates and their surroundings, performing a postmortem examination, and collecting samples. The article also describes and illustrates some of the gross pathology likely to be seen in food animals with neurologic diseases. It also emphasizes that not all neurologic diseases are accompanied by pathology of the central nervous system and that it is important to examine and sample the entire animal. 


\section{References}

1. Radostits OM, Gay CC, Blood DC, Hinchcliff KW. Diseases of the nervous system. In: Veterinary Medicine. A textbook of the diseases of cattle, sheep, pigs, goats and horses. London, W. B. Saunders; 1999. p. 501-549.

2. Constable PD. Clinical examination of the ruminant nervous system. Vet Clin North Am Food Anim Pract 2004;20:185-14..

3. Scott PR. Diagnostic techniques and clinicopathologic findings in ruminant neurologic disease. Vet Clin North Am Food Anim Pract 2004;20:215-30.

4. Stokol T, Divers TJ, Arrigan JW, McDonough SP. Cerebrospinal fluid findings in cattle with central nervous system disorders: a retrospective study of 102 cases (1990-2008). Vet Clin Pathol 2009;38:103-12.

5. D'Angelo A, Miniscalco B, Bellino C, et al. Analysis of cerebrospinal fluid from 20 calves after storage for 24 hours. Vet Rec 2009;164:491-93.

6. Andrews JL, Van Alstine WG, Schwartz KJ: A basic approach to food animal necropsy. Vet Clin North Am Food Anim Pract 1986;2:1-29

7. Johnson DD, Libal MC. Necropsy of sheep and goats. Vet Clin North Am Food Anim Pract $1986 ; 2: 129-46$.

8. Thacker HL. Necropsy of the feeder pig and adult swine. Vet Clin North Am Food Anim Pract 1986;2:173-86.

9. Mason GL, Madden DJ: Performing the field necropsy examination. Vet Clin North Am Food Anim Pract 2007;23:503-26 
10. Nietfeld, JC. Field Necropsy Techniques and Proper Specimen Submission for Investigation of Emerging Infectious Diseases of Food Animals. Vet Clin North Am Food Anim Pract 2010;26:1-13.

11. Cornell University College of Veterinary Medicine website. Virtual vet: bovine necropsy module. Available at: http://video.vet.cornell.edu/virtualvet/bovine/chapters1-4.html. Accessed January 15, 2012.

12. McCoy MA, Hutchinson T, Davidson G, et al. Postmortem biochemical markers of experimentally induced hypomagnesaemic tetany in cattle. Vet Rec 2001;148:268-73.

13. McCoy MA. Hypomagnesaemia and new data on vitreous humor magnesium concentration as a post-mortem marker in ruminants. Magnesium Res 2004;17(2):137-45.

14. Callan RJ, Van Metre DC. Viral diseases of the ruminant nervous system. Vet Clin North Am Food Anim Pract 2004;20:327-62.

15. Center for Disease Control website. Protocol for postmortem diagnosis of rabies in animals by direct fluorescent antibody testing. Available at: http://www.cdc.gov/rabies/pdf/rabiesdfaspv2.pdf. Accessed January 15, 2012.

16. Morin DE. Brainstem and cranial nerve abnormalities: listeriosis, otitis media/interna, and pituitary abscess syndrome. Vet Clin North Am Food Anim Pract 2004;20:243-73.

17. Maxie MG, Youssef S. Nervous System. In: Maxie MG, editor. Jubb, Kennedy, and Palmer's Pathology of Domestic Animals, 5th edition, vol. 1. Philadephia: Elsevier Saunders; 2007. p. 281-457.

18. Summers BA, CummingsJF, de Lahunta A. Malformations of the central nervous system. In: Veterinary Neuropathology. St. Louis: Mosby; 1995. p. 68-94. 
19. Kupferschmidt K. New animal virus takes northern Europe by Surprise. Science Now 2012, January. Available at: http://news.sciencemag.org/sciencenow/2012/01/new-animalvirus-takes-northern-.html. Accessed January 20, 2012.

20. Washburn KE, Streeter RN. Congenital defects of the ruminant nervous system. Vet Clin North Am Food Anim Pract 2004;20:313-34.

21. Summers BA, CummingsJF, de Lahunta A. Degenerative diseases of the central nervous system. In: Veterinary Neuropathology. St. Louis: Mosby; 1995. p. 208-350.

22. Thompson K. Bones and joints. In: Maxie MG, editor. Jubb, Kennedy, and Palmer's Pathology of Domestic Animals, 5th edition, vol. 1. Philadephia: Elsevier Saunders; 2007. p. $1-184$.

23. Packer RA. Congenital and inherited anomalies of the nervous system. In: Kahn CM, editor. The Merck Veterinary Manual, 10th edition, Whitehouse Station, NJ: Merck \& Co; 2010. p. 1118-31. 
Table 1: Diagnosis of Secondary, Metabolic, and Toxic Neurologic Diseases

\begin{tabular}{|c|c|c|c|}
\hline Disease/Condition & $\begin{array}{l}\text { Location of } \\
\text { Primary Lesions }\end{array}$ & Lesions in CNS & Diagnosis \\
\hline $\begin{array}{l}\text { Nervous } \\
\text { coccidiosis in } \\
\text { calves }\end{array}$ & Spiral colon & No & $\begin{array}{l}\text { 1. Clinical signs } \\
\text { 2. Identify coccidial infection } \\
\text { 2. Rule out primary CNS disease }\end{array}$ \\
\hline $\begin{array}{l}\text { Edema disease in } \\
\text { pigs }\end{array}$ & $\begin{array}{l}\text { Edema of brain, } \\
\text { stomach, } \\
\text { mesocolon, eyelids }\end{array}$ & $\begin{array}{l}\text { Microscopic: } \\
\text { Vascular necrosis, } \\
\text { edema, focal malacia }\end{array}$ & $\begin{array}{l}\text { 1. Isolation of Shiga toxin producing } \\
\text { Escherichia coli from small intestine, } \\
\text { 2. Acute CNS signs and typical } \\
\text { lesions }\end{array}$ \\
\hline $\begin{array}{l}\text { Enterotoxemia -- } \\
\text { Clostridium } \\
\text { perfringens type D }\end{array}$ & $\begin{array}{l}\text { Excess fluid in } \\
\text { pericardial sac, } \\
\text { abdomen, thorax }\end{array}$ & $\begin{array}{l}\text { Focal symmetrical } \\
\text { hemorrhage and } \\
\text { malacia }\end{array}$ & $\begin{array}{l}\text { 1. Identify toxin in intestinal } \\
\text { contents } \\
\text { 2. Isolate type } \mathrm{Cl} \text {. perfringens type D } \\
\text { from intestines, } \\
\text { 3. Microscopic lesions in brain }\end{array}$ \\
\hline $\begin{array}{l}\text { Tetanus }-\mathrm{Cl} \text {. } \\
\text { tetani }\end{array}$ & $\begin{array}{l}\text { Infected wound; } \\
\text { often no lesion }\end{array}$ & No & $\begin{array}{l}\text { 1. Clinical signs-most common, } 2 \text {. } \\
\text { Isolation of } \mathrm{Cl} \text {. tetani from wound }\end{array}$ \\
\hline $\begin{array}{l}\text { Botulism-Cl. } \\
\text { botulinum }\end{array}$ & $\begin{array}{l}\text { Ingestion of } \mathrm{Cl} \text {. } \\
\text { botulinum toxin }\end{array}$ & No & $\begin{array}{l}\text { 1. Clinical signs } \\
\text { 2. Identify toxin in serum by mouse } \\
\text { inoculation or ELISA }\end{array}$ \\
\hline $\begin{array}{l}\text { Lead toxicity-- } \\
\text { ruminants }\end{array}$ & $\begin{array}{l}\text { Vascular-cerebral } \\
\text { edema }\end{array}$ & $\begin{array}{l}\text { Usually no lesions } \\
\text { Laminar necrosis } \\
\text { possible }\end{array}$ & $\begin{array}{l}\text { Determination of lead levels in: } \\
\text { 1. whole blood } \\
\text { 2. kidney }\end{array}$ \\
\hline
\end{tabular}




\begin{tabular}{|c|c|c|c|}
\hline & & & 3. liver (kidney is preferred) \\
\hline $\begin{array}{l}\text { Sodium toxicity } \\
\text { due to water } \\
\text { deprivation --pigs }\end{array}$ & Cerebrum & $\begin{array}{l}\text { Laminar necrosis, } \\
\text { eosinophilic } \\
\text { inflammation }\end{array}$ & $\begin{array}{l}\text { 1. Brain Na levels } \\
\text { 2. Histologic lesions in brain } \\
\text { 3. Serum and CSF Na often } \\
\text { diagnostic }\end{array}$ \\
\hline $\begin{array}{l}\text { Sodium toxicity } \\
\text { due to excess } \mathrm{Na} \\
\text { intake }\end{array}$ & Uncertain & $\begin{array}{l}\text { No (sometimes } \\
\text { laminar necrosis) }\end{array}$ & $\begin{array}{l}\text { 1.Brain Na levels } \\
\text { 2. Serum or CSF Na levels }\end{array}$ \\
\hline $\begin{array}{l}\text { Hypomagnesemic } \\
\text { tetany-ruminants }\end{array}$ & None & No & $\begin{array}{l}\text { 1. Serum or plasma Mg levels--living } \\
\text { 2. Vitreous humor Mg levels }\end{array}$ \\
\hline $\begin{array}{l}\text { Hypoglycemia-- } \\
\text { neonatal pigs, } \\
\text { ketosis, pregnancy } \\
\text { toxemia }\end{array}$ & None & No & $\begin{array}{l}\text { 1. History } \\
\text { 2. Hypoglycemia } \\
\text { 3. Ketones in urine }\end{array}$ \\
\hline Anaplasmosis & $\begin{array}{l}\text { Anemia resulting in } \\
\text { cerebral hypoxia }\end{array}$ & No & $\begin{array}{l}\text { 1. Verify anemia } \\
\text { 2. Identify parasite in blood smear } \\
\text { 3. ELISA, PCR of whole blood }\end{array}$ \\
\hline $\begin{array}{l}\text { Organophosphage } \\
\text { and carbamate } \\
\text { toxicity }\end{array}$ & None & No & $\begin{array}{l}\text { 1. Whole blood cholinesterase level } \\
\text { 2. Brain cholinesterase level } \\
\text { 3. Identification of agent in } \\
\text { stomach/rumen contents, tissues, } \\
\text { and/or source }\end{array}$ \\
\hline Selenium toxicity & Separation hoof & Necrosis in ventral & Selenium levels in blood, serum, or \\
\hline
\end{tabular}




\begin{tabular}{|l|l|l|l|}
\hline in pigs & wall from skin & horns of spinal cord & tissues \\
\hline Nonprotein & Excessive ammonia & Microscopic: Spongy & 1. Rumen pH 7.5-8 at time of death \\
& released in the & degeneration of & is presumptive \\
& gastrointestinal & white matter & 2. Measurement of ammonia levels \\
& tract with & possible & in rumen contents, serum, blood- \\
& hyperammonemia & & must be within 12 hours of death or \\
& & & 2 hours in hot weather \\
\hline
\end{tabular}




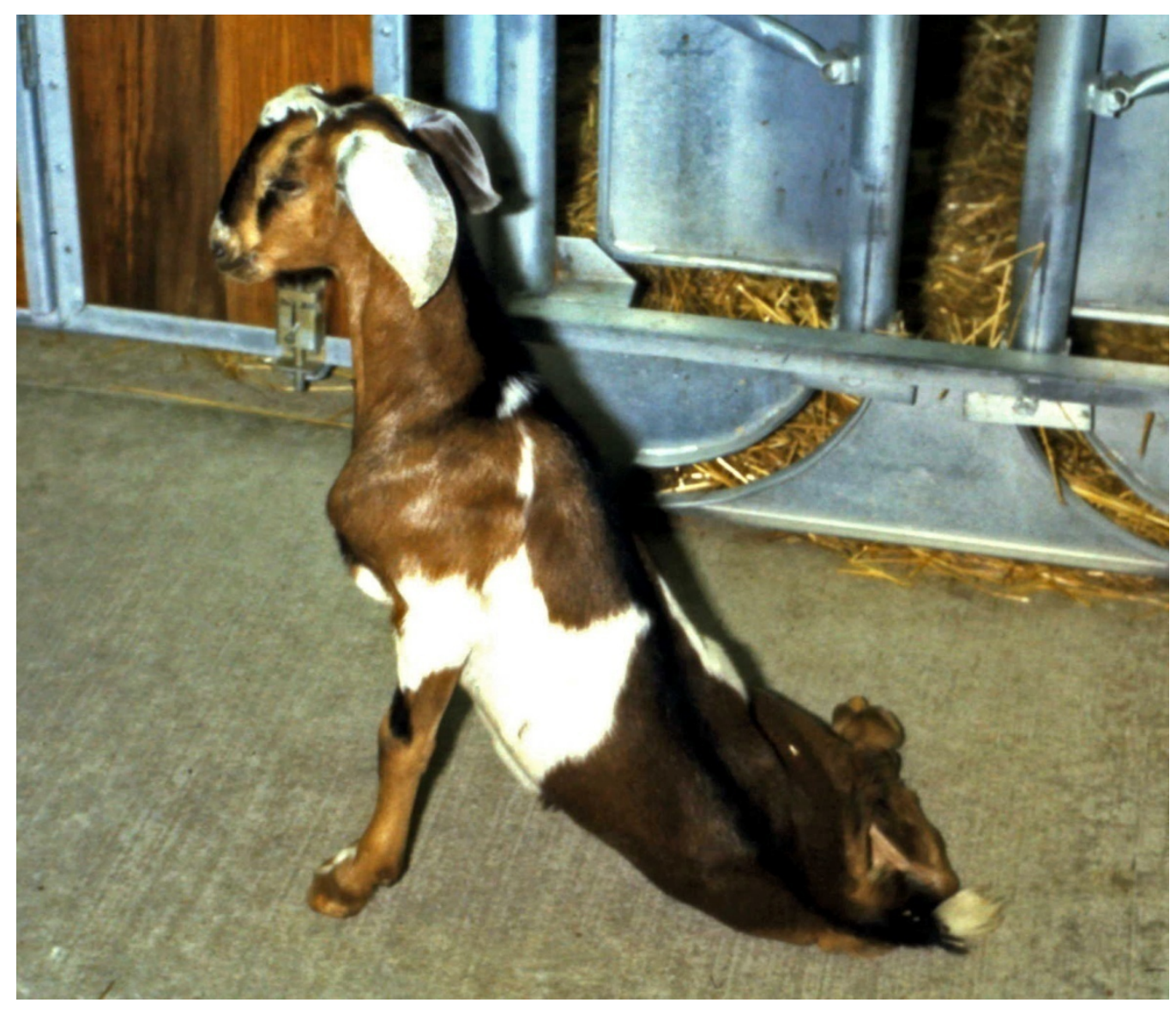

Fig. 1. A young goat with paralysis of the rear legs caused by caprine arthritis-encephalitis (CAE) virus, which causes patchy demyelination and nonsuppurative encephalomyelitis. Clinically, trauma to the vertebral column and spinal cord could cause the same symptoms. 


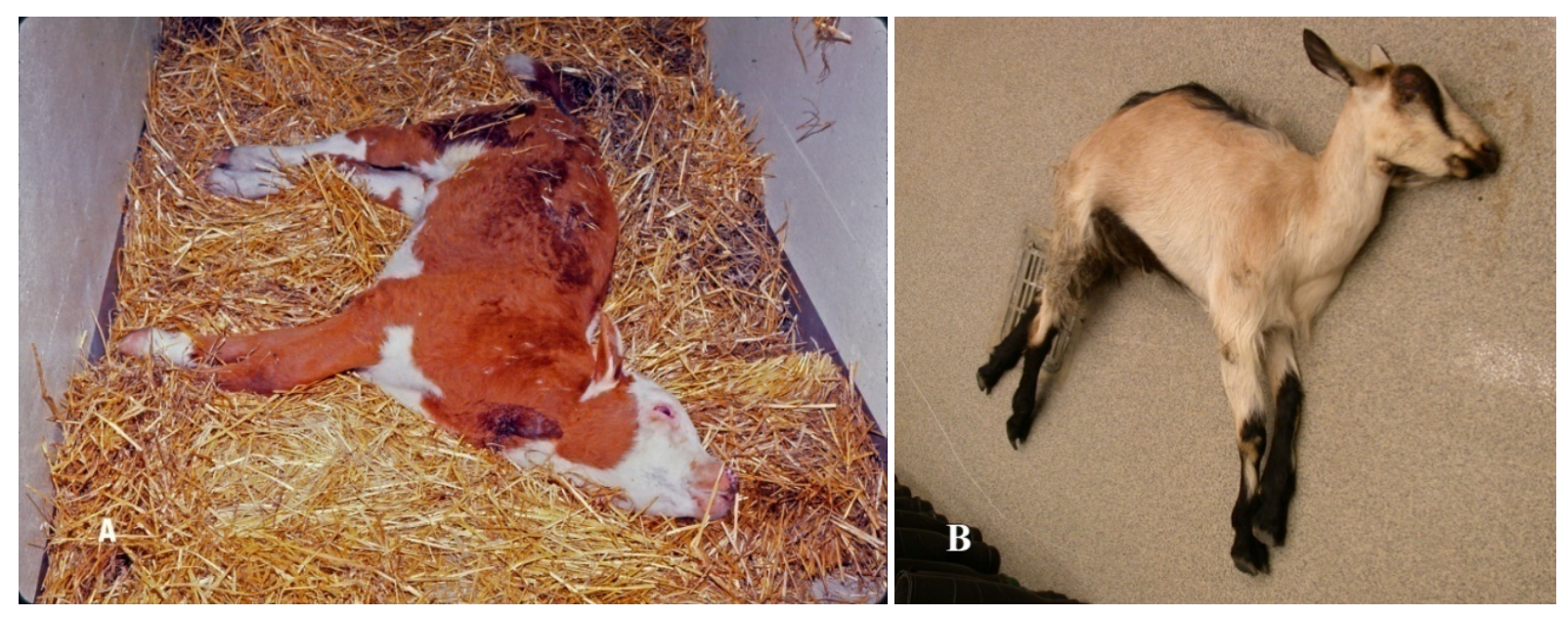

Fig. 2. A. Calf with tetanus. B. Kid with bacterial meningitis. 


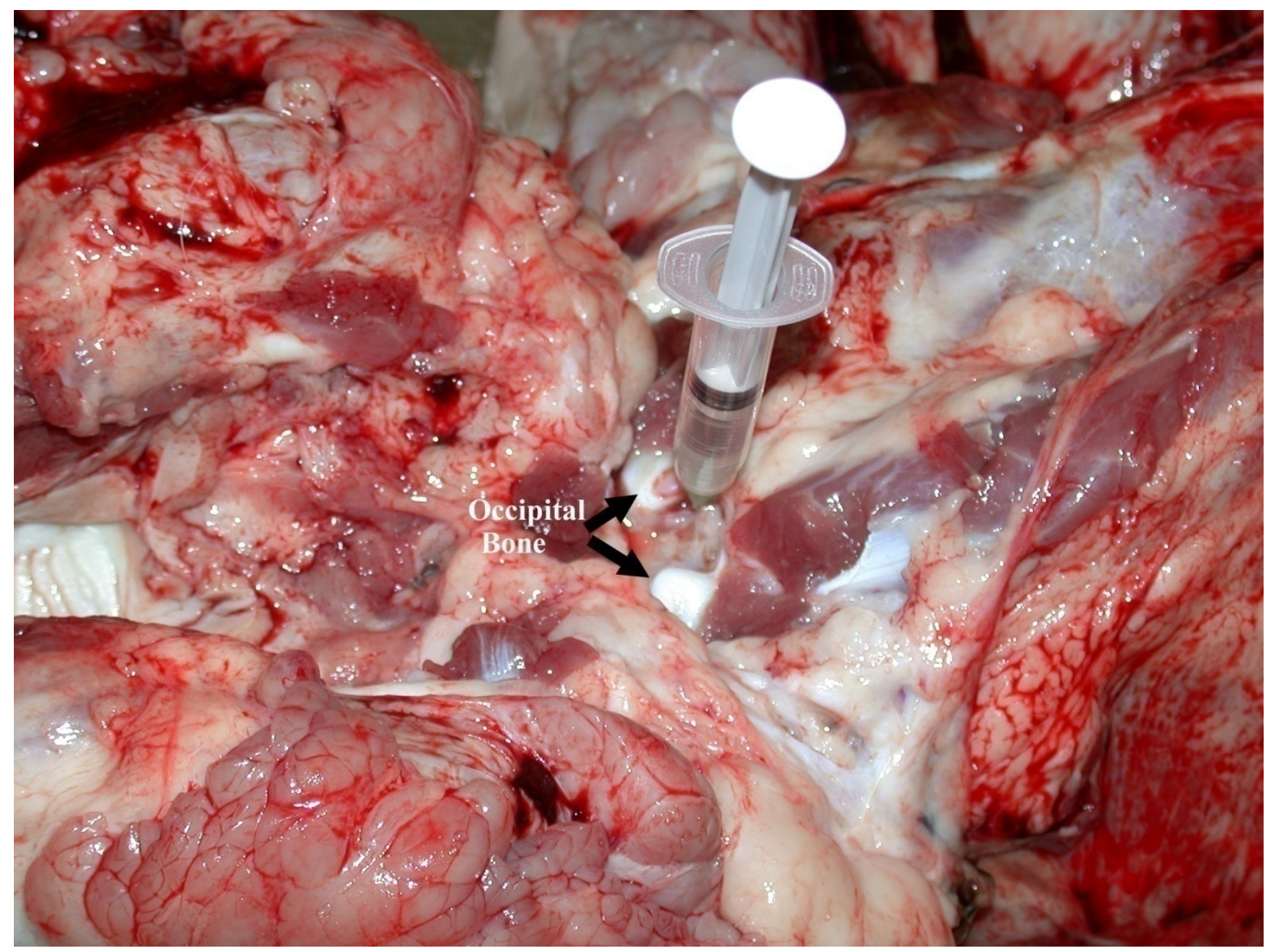

Fig. 3. Collection of CSF fluid from the atlanto-occipital joint. By inserting the needle off center the likelihood of aspirating blood is decreased. 


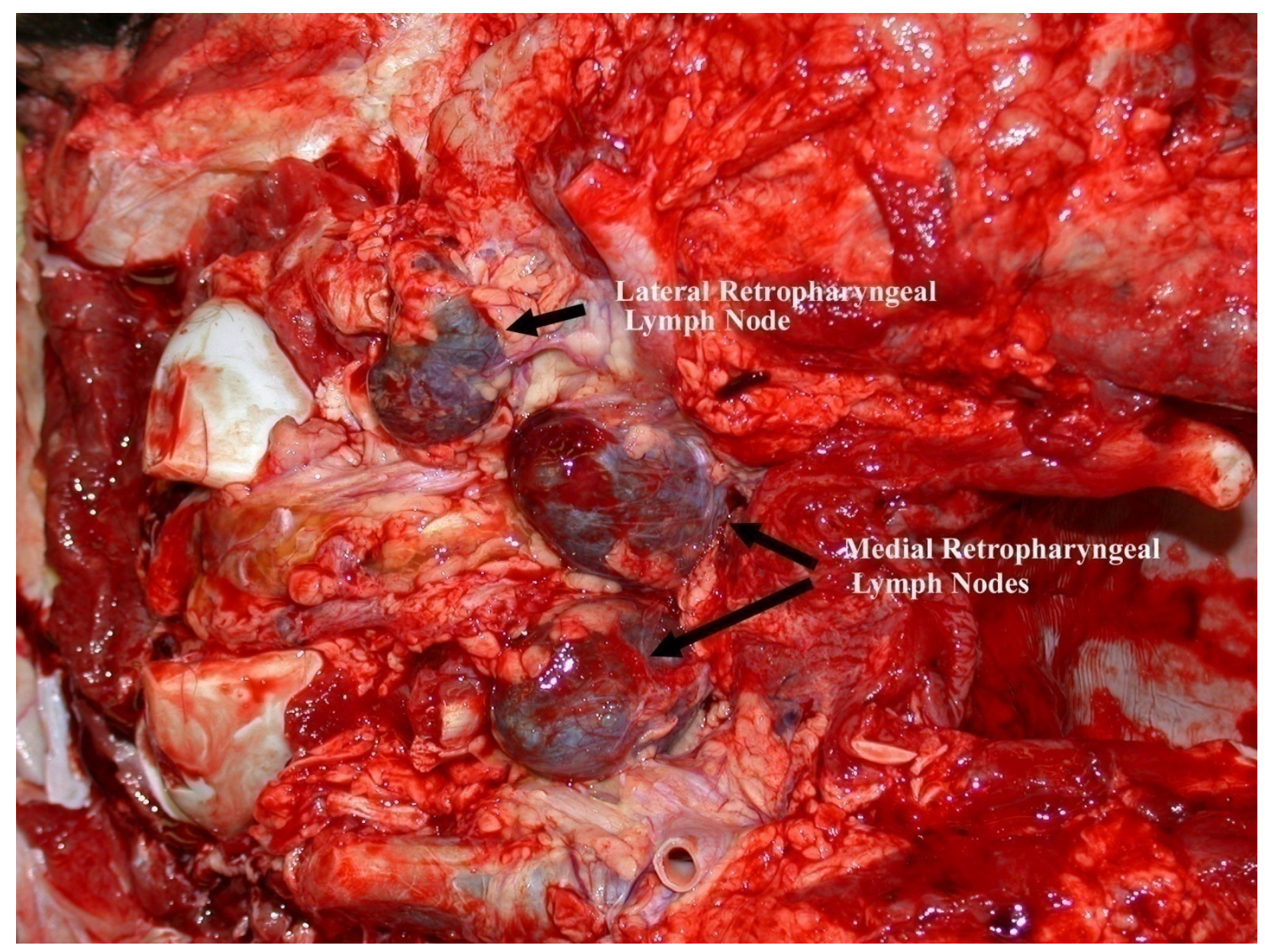

Fig. 4. Retropharyngeal lymph nodes. One lateral retropharyngeal node has been removed. These lymph nodes are located just caudal and dorsal to the pharynx and are used to test for scrapie in sheep and goats, and for chronic wasting disease in cervids. 


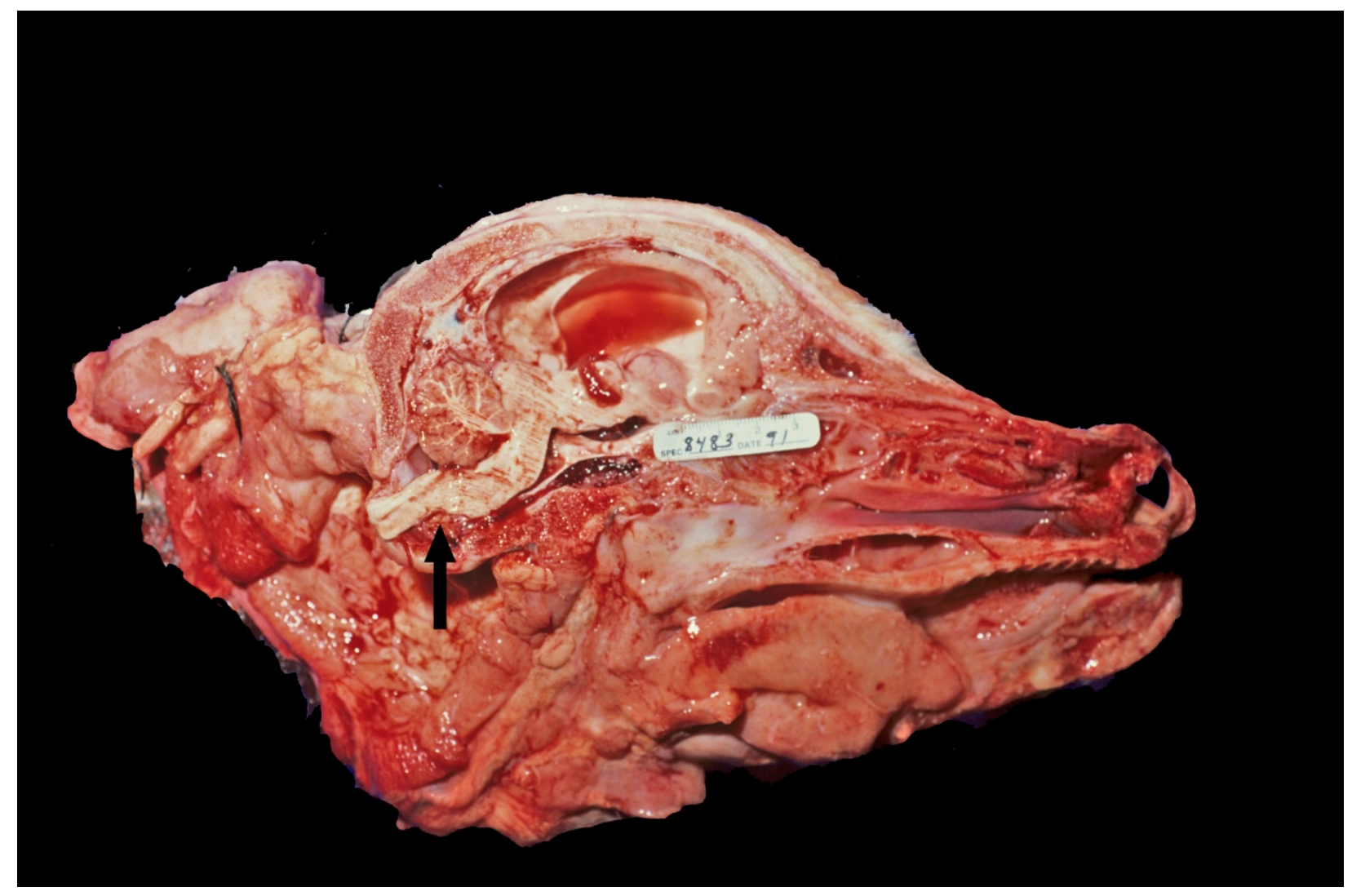

Fig. 5. Head from a calf with hydrocephalus that has been split lengthwise on the midline. Note the acute, upward deviation of the brainstem (arrow) which restricts flow of CSF resulting in hydrocephalus. 


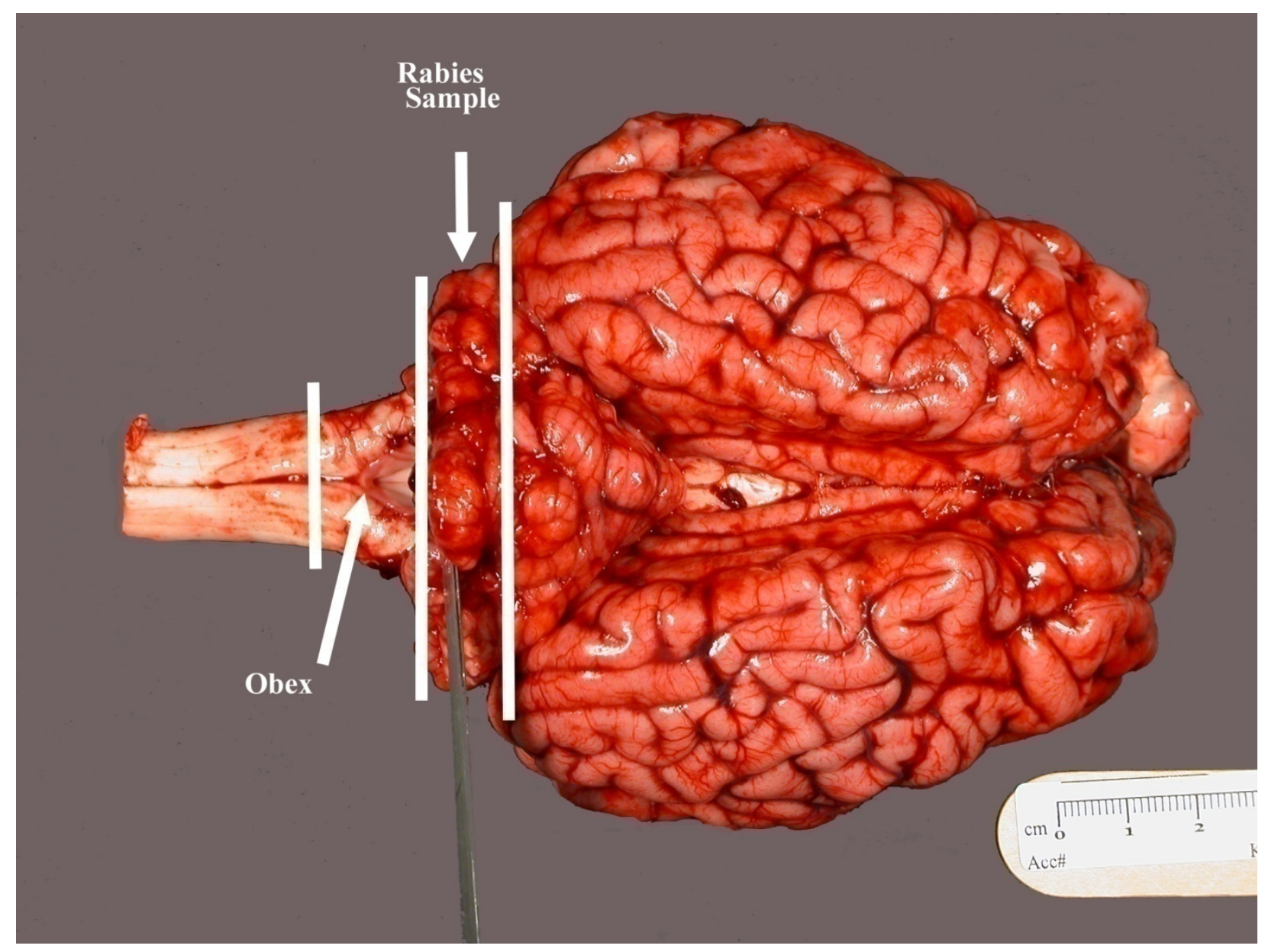

Fig. 6. Brain from a calf demonstrating where to cut to obtain samples for rabies and transmissible spongiform encephalopathy (TSE) tests. A section through the cerebellum and underlying brainstem is the preferred sample for rabies and the obex is necessary for TSE tests. 

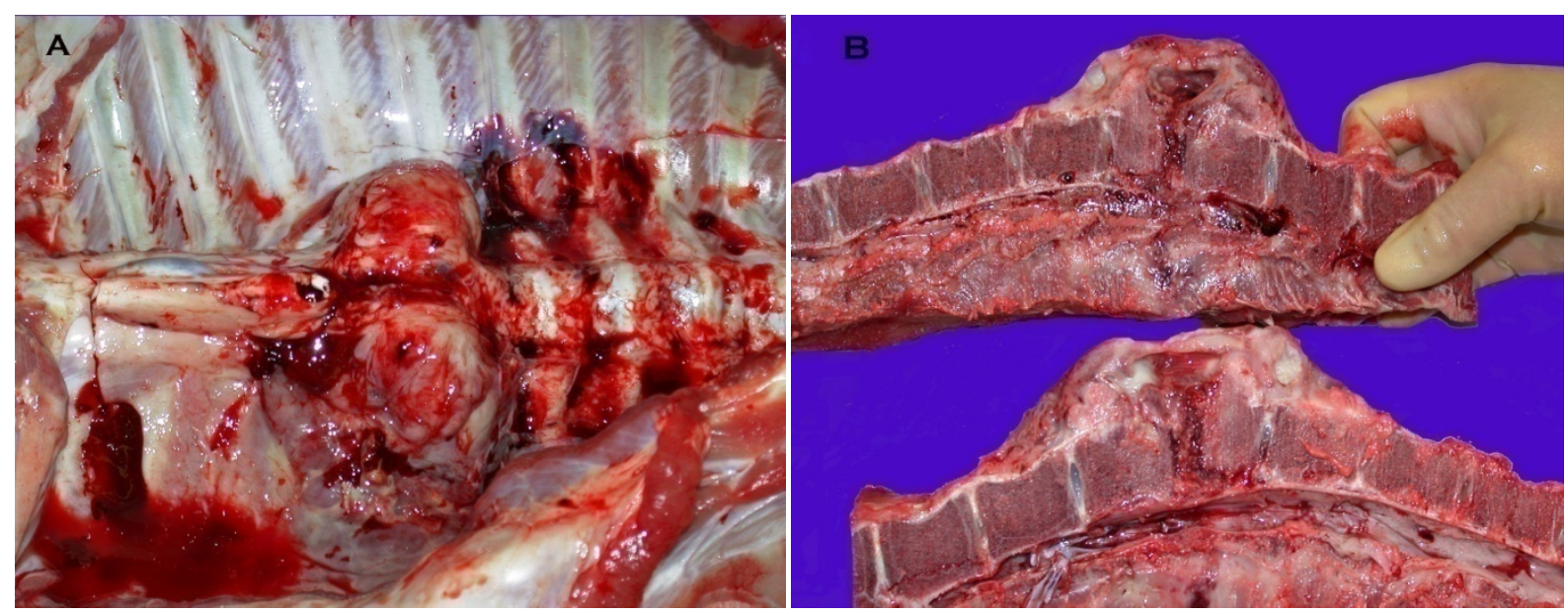

Fig. 7. Abscesses involving thoracic vertebral bodies of a pig with paralysis of the rear legs. In 7A the abscesses bulge into the thoracic cavity alleviating the need to open the spinal canal to determine the cause of the paralysis. In $7 \mathrm{~B}$, the vertebral bodies have been sectioned with a handsaw to demonstrate the extent of involvement by the abscesses. 

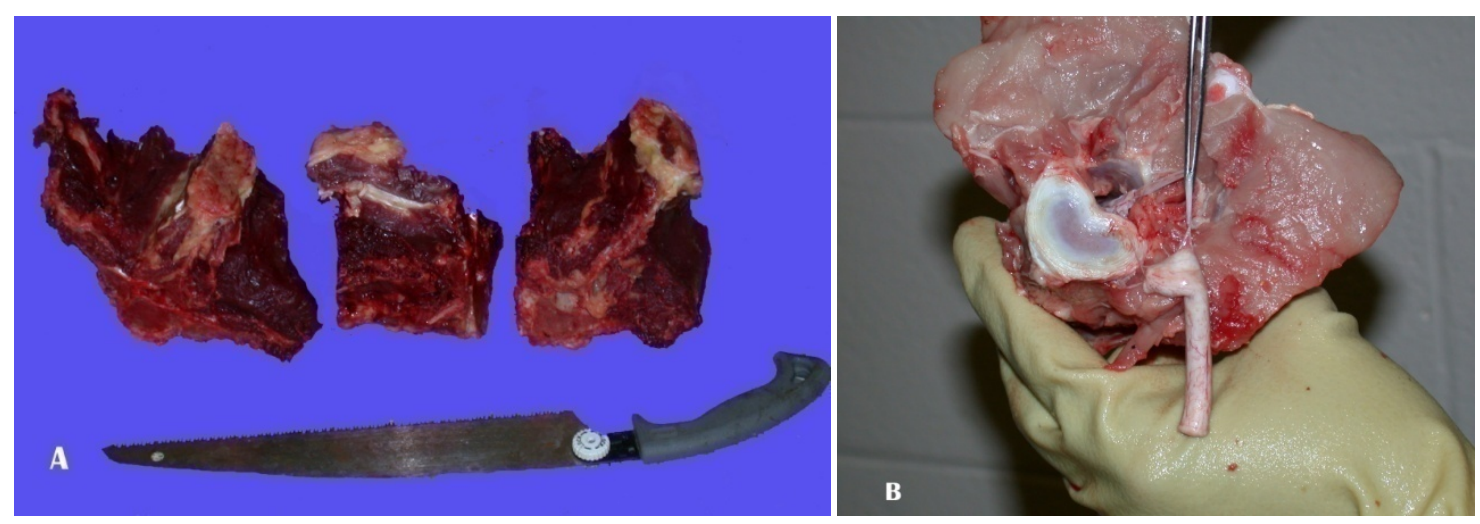

Fig. 8. A. Sections of spinal column from a feeder calf removed with a handsaw. B. Remove the spinal cord by cutting the nerve rootlets with a small scissors and retracting the cord with a forceps. Portions of each section of cord can be submitted fresh and formalin-fixed. 


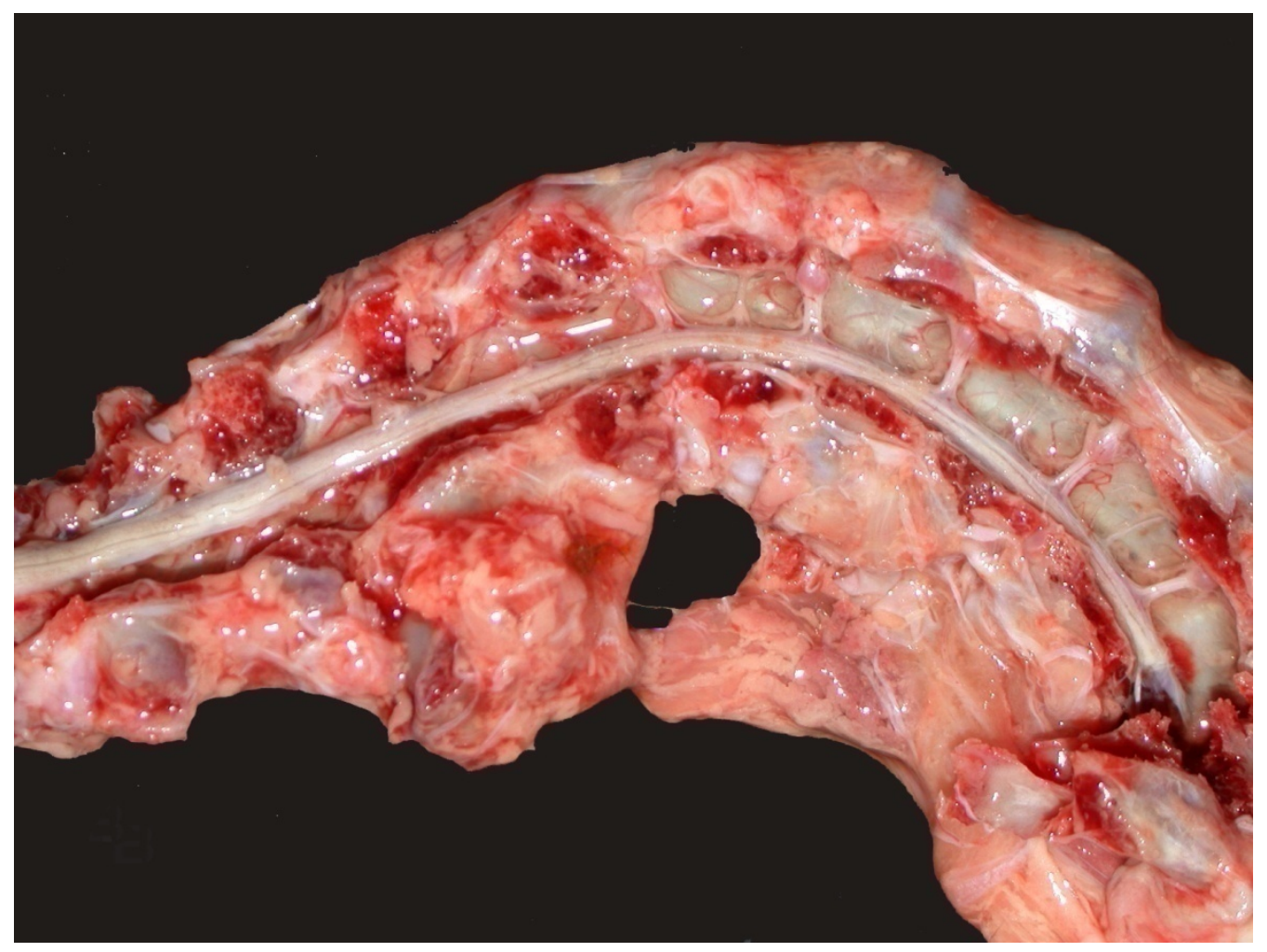

Fig. 9. Spinal cord within the vertebral canal of a stillborn lamb infected in utero by Cache Valley virus. The cord was exposed by removing the dorsal arches with diagonal pliers. Note the small size of the spinal cord in comparison to the spinal canal; normally, the spinal cord fills the spinal canal. This lamb was also affected by severe hydranencephaly and its brain is shown in Fig. 17A . 


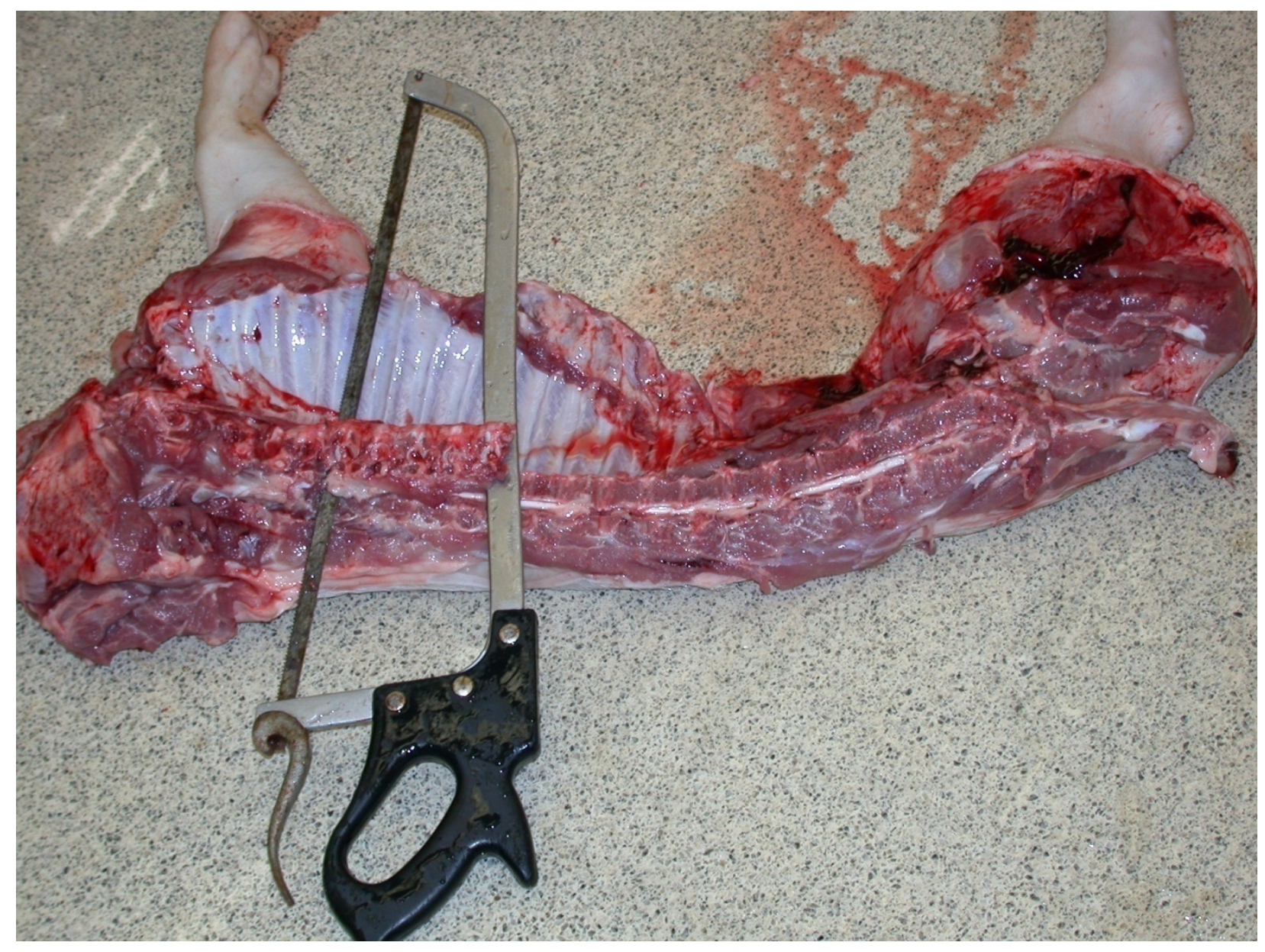

Fig. 10. Removing the spinal cord from a pig with a hand saw. The technique also works well to examine and remove the spinal cord of young calves. 


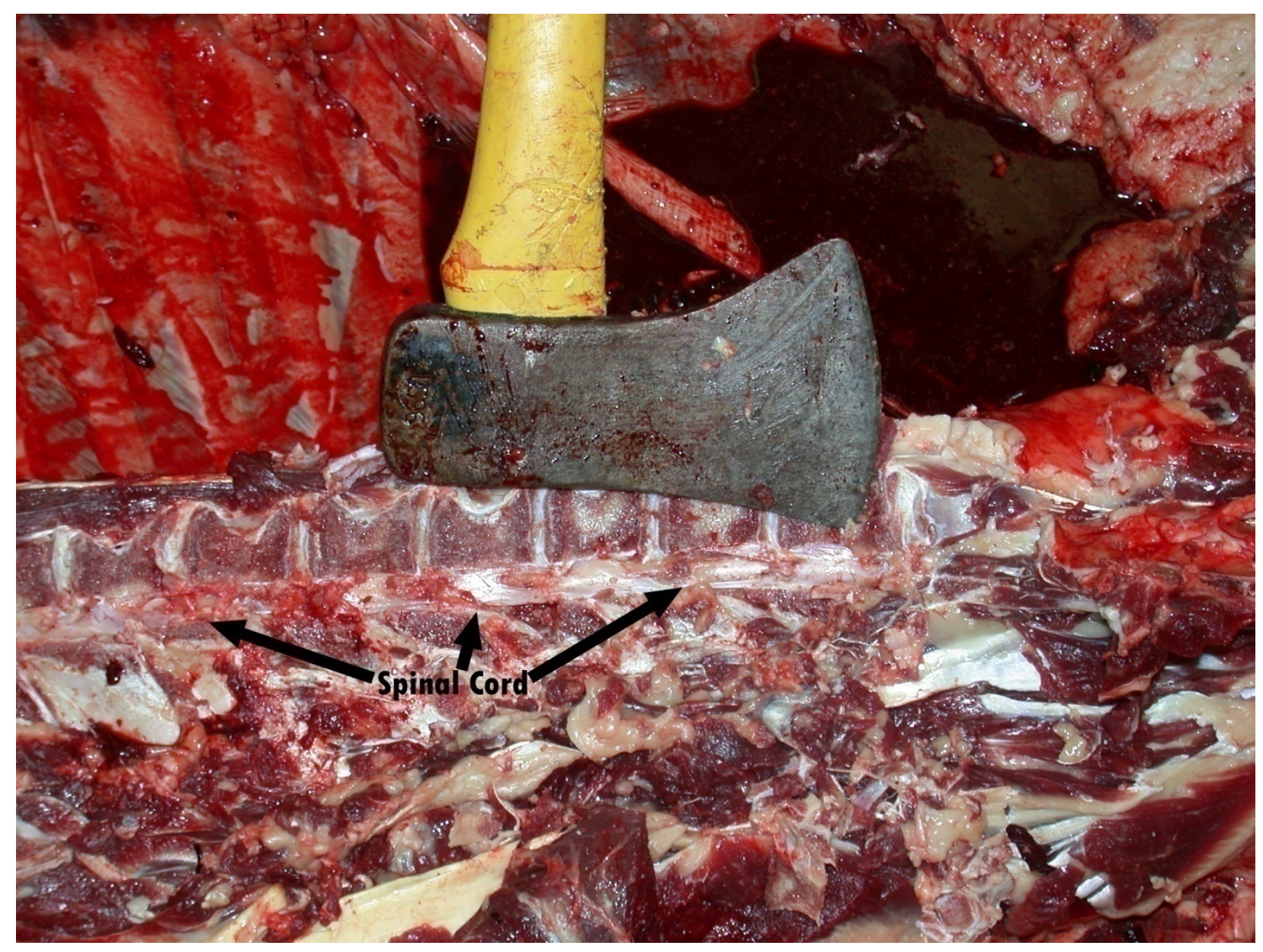

Fig. 11. Removing the spinal cord from a cow by removing the lateral processes and lateral portions of the vertebral bodies with an axe. 


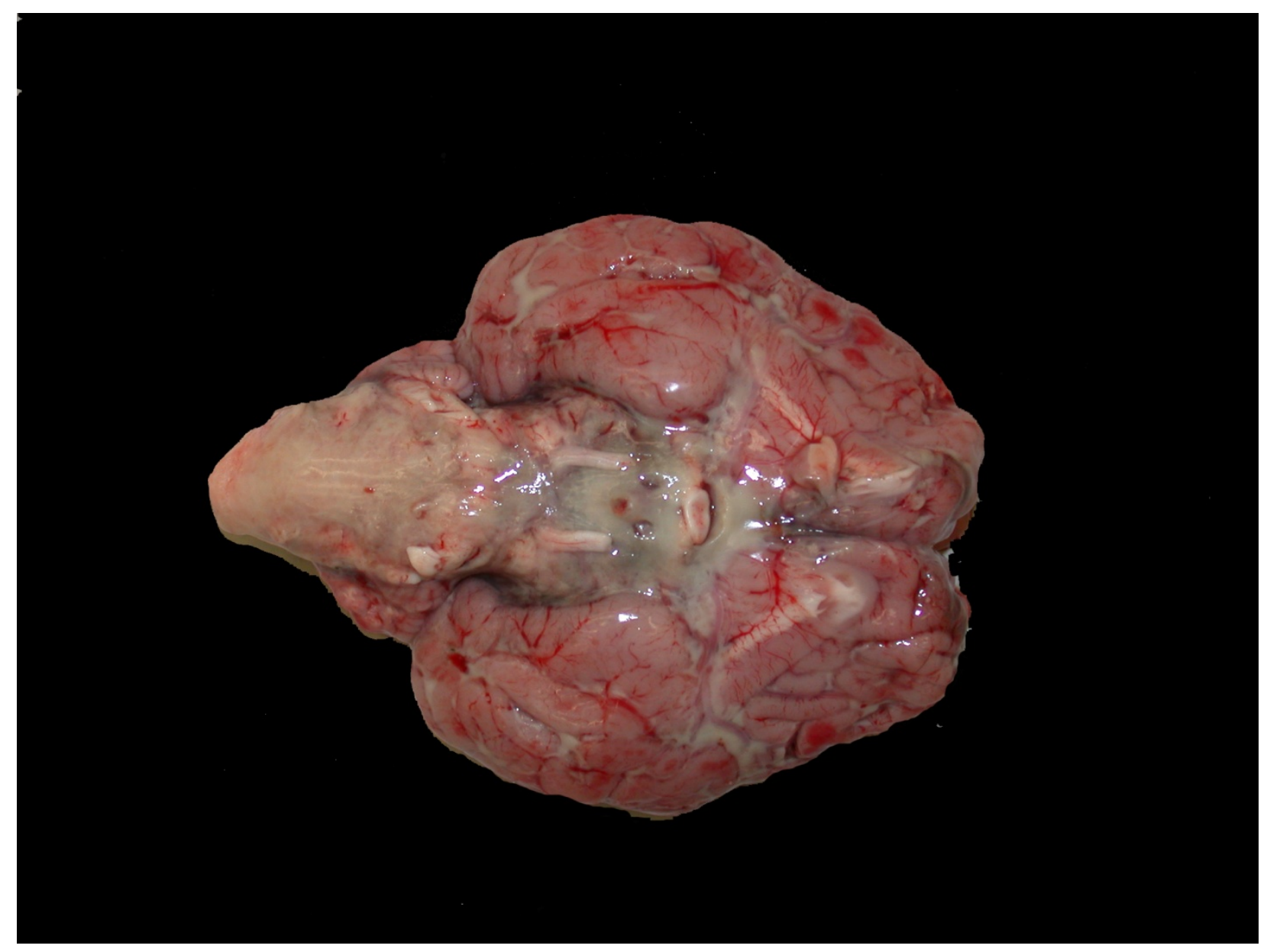

Fig. 12. Cloudy, greenish exudates on the ventral surface of a calf brain with bacterial meningitis. 

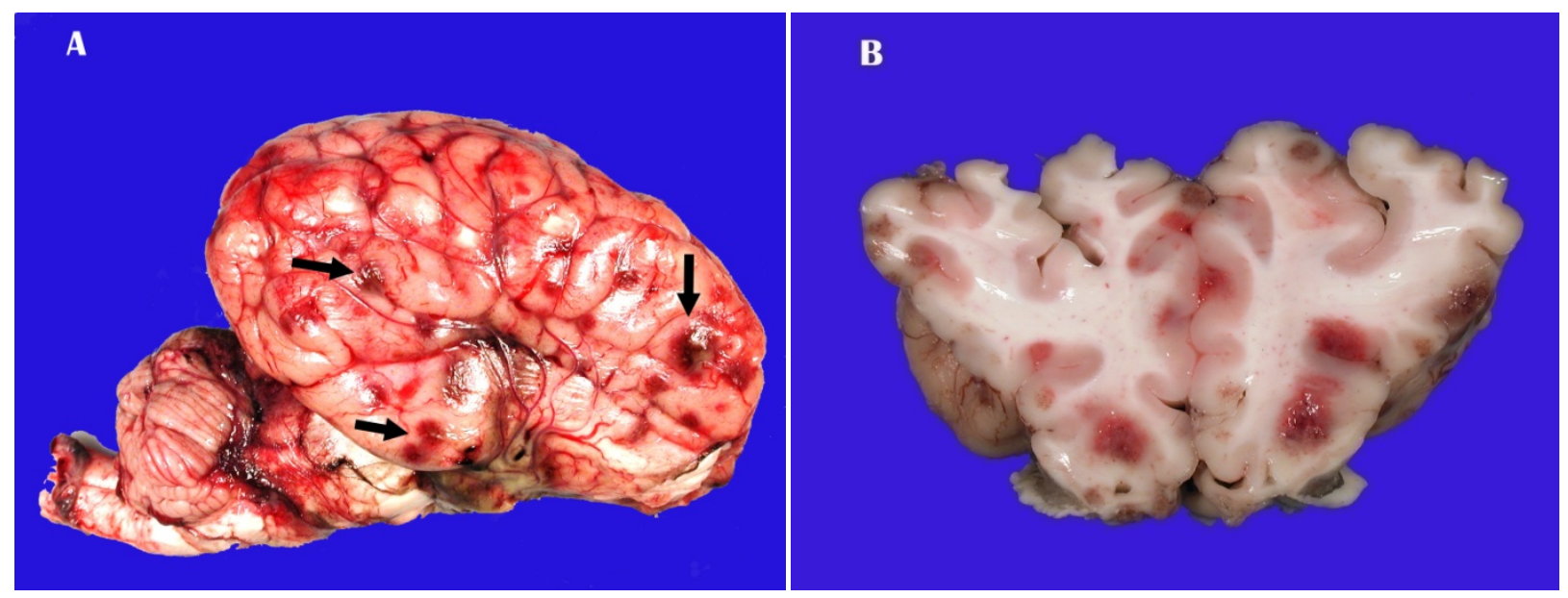

Fig. 13. Multiple acute hemorrhages on the outer surface (A; arrows) and cut surfaces (B) of a feedlot calf with thrombotic meningoencephalitis caused by Histophilus somni. (Photographs courtesy of Drs. Gordon Andrews and Giselle Cino) 


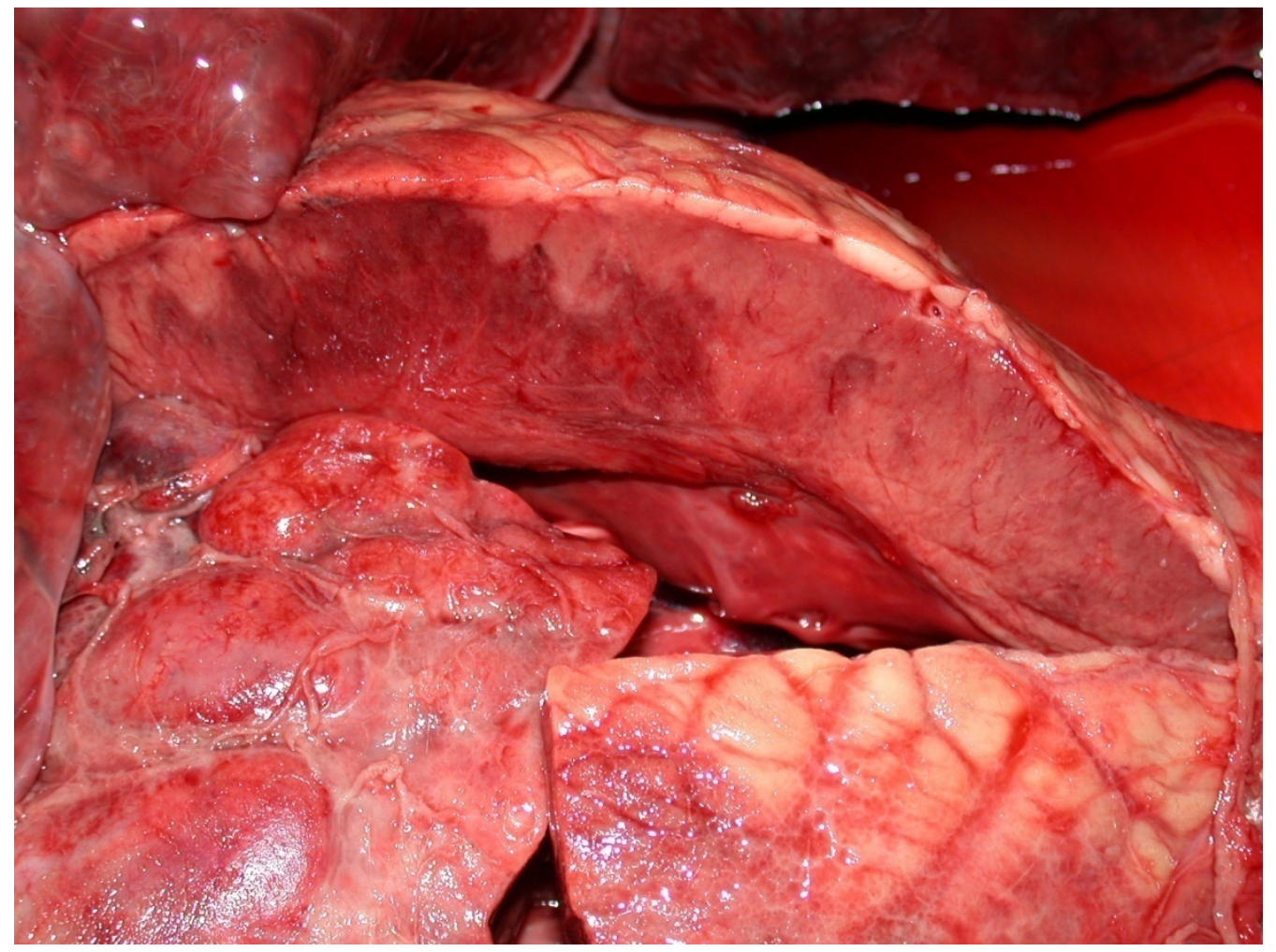

Fig. 14. Acute hemorrhage in the ventricular free wall of a feedlot calf with thrombotic meningoencephalitis caused by systemic $H$. somni infection. This is a lesion frequently seen in calves with CNS involvement. 


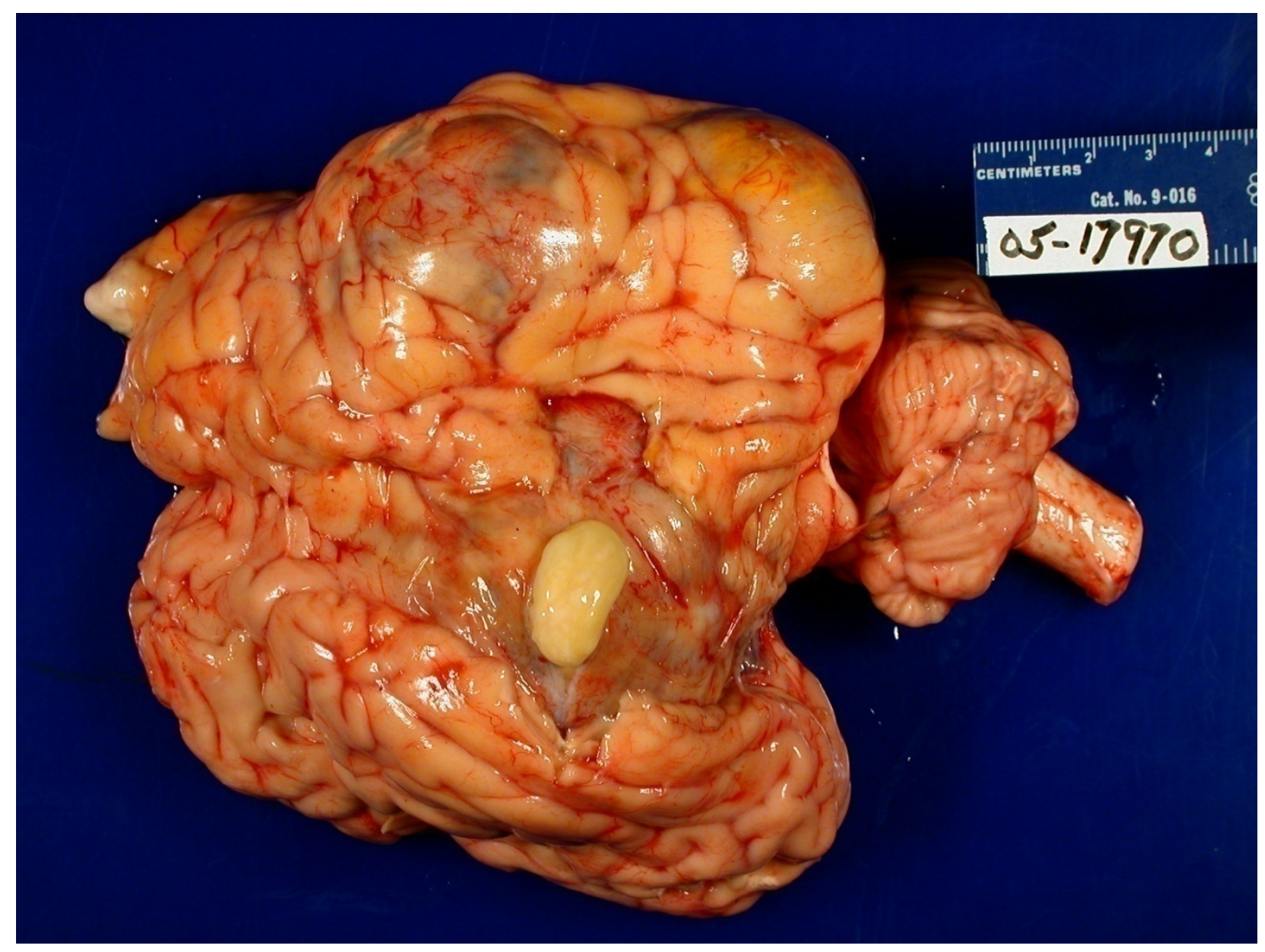

Fig. 15. Abscess involving both lateral ventricles of a neonatal calf. Note the swellings involving the right cerebral cortex and the purulent exudates exuding from the incised left lateral ventricle. 


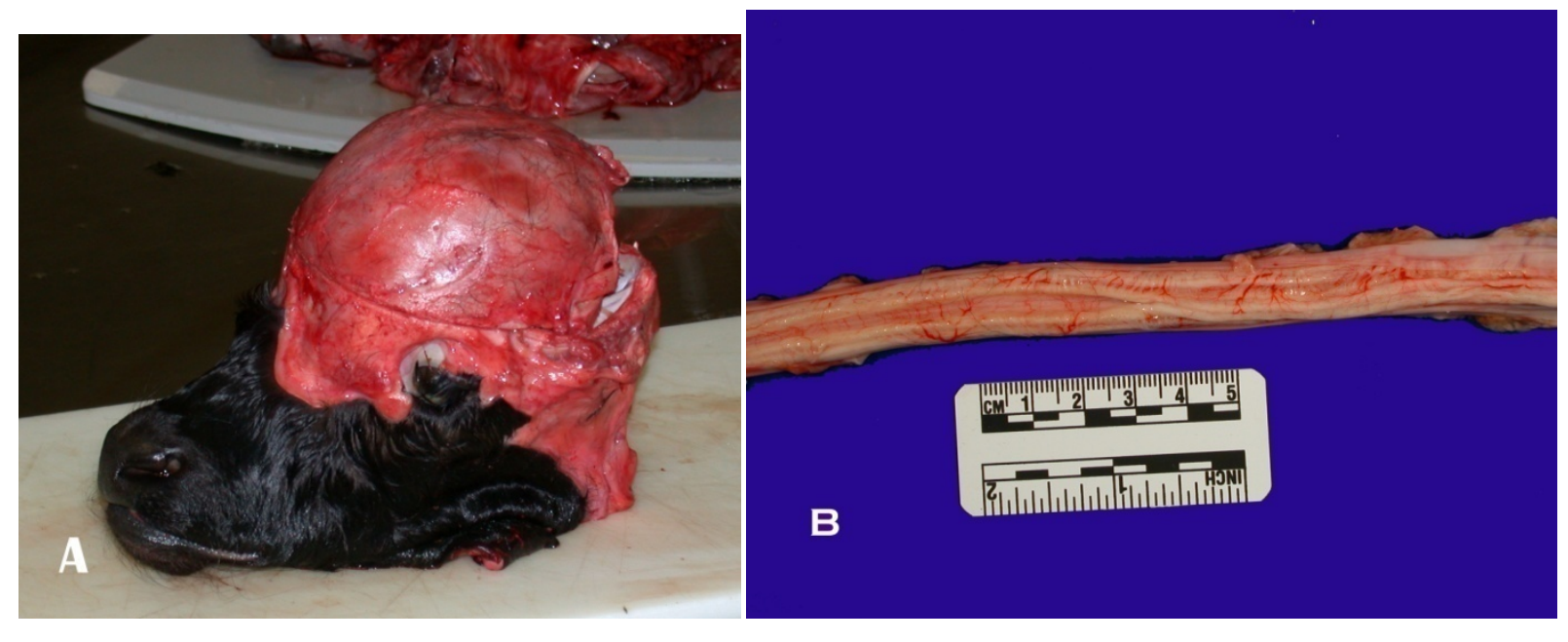

Fig. 16. Internal hydrocephalus in a calf resulting in doming of the cranium (A) which was caused by myelodysplasia with incomplete closure of the thoracolumbar spinal cord (B) and regional lack of the central canal. 

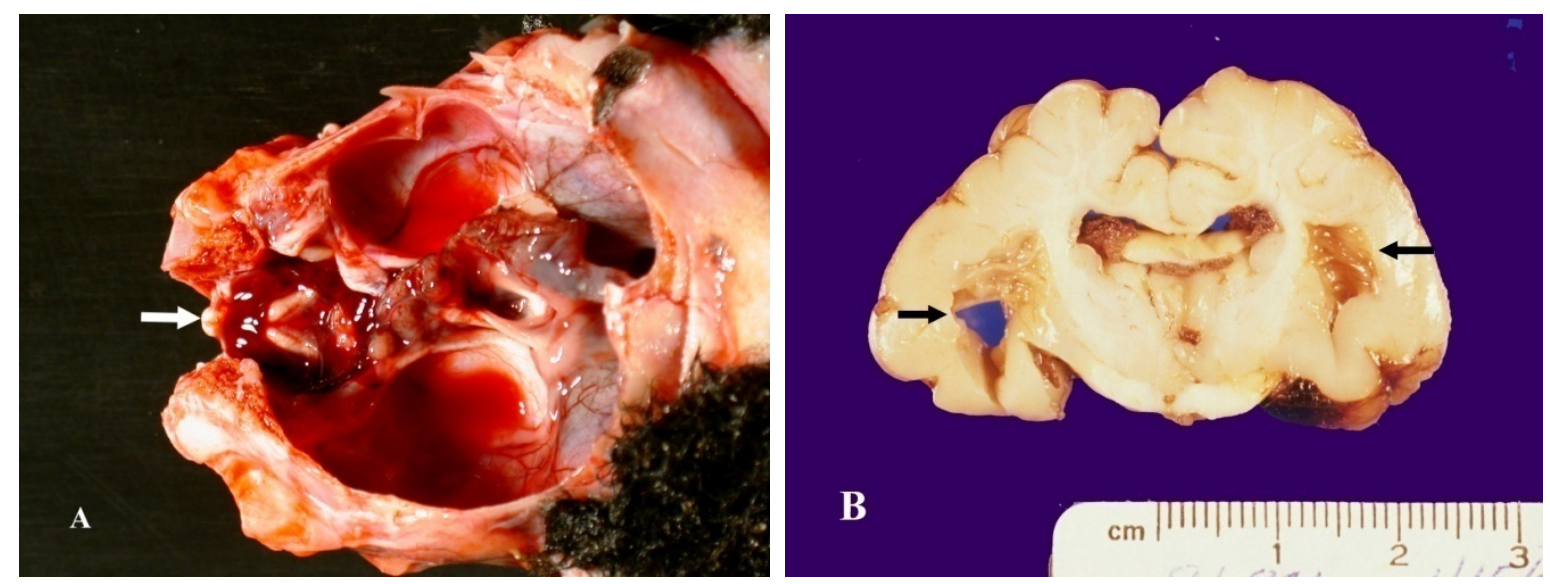

Fig. 17. A. Severe hydranencephaly in a lamb infected in utero with Cache Valley Virus. The cerebrum consisted of a thin, membranous sac filled with CSF, which ruptured when the skull was opened. The cerebellum is severely atrophied and the only relatively normal portion of the brain is the brainstem (arrow). B. Porencephaly in a lamb infected in utero with Cache Valley virus. Note the holes (arrows) in the cerebral cortex. 


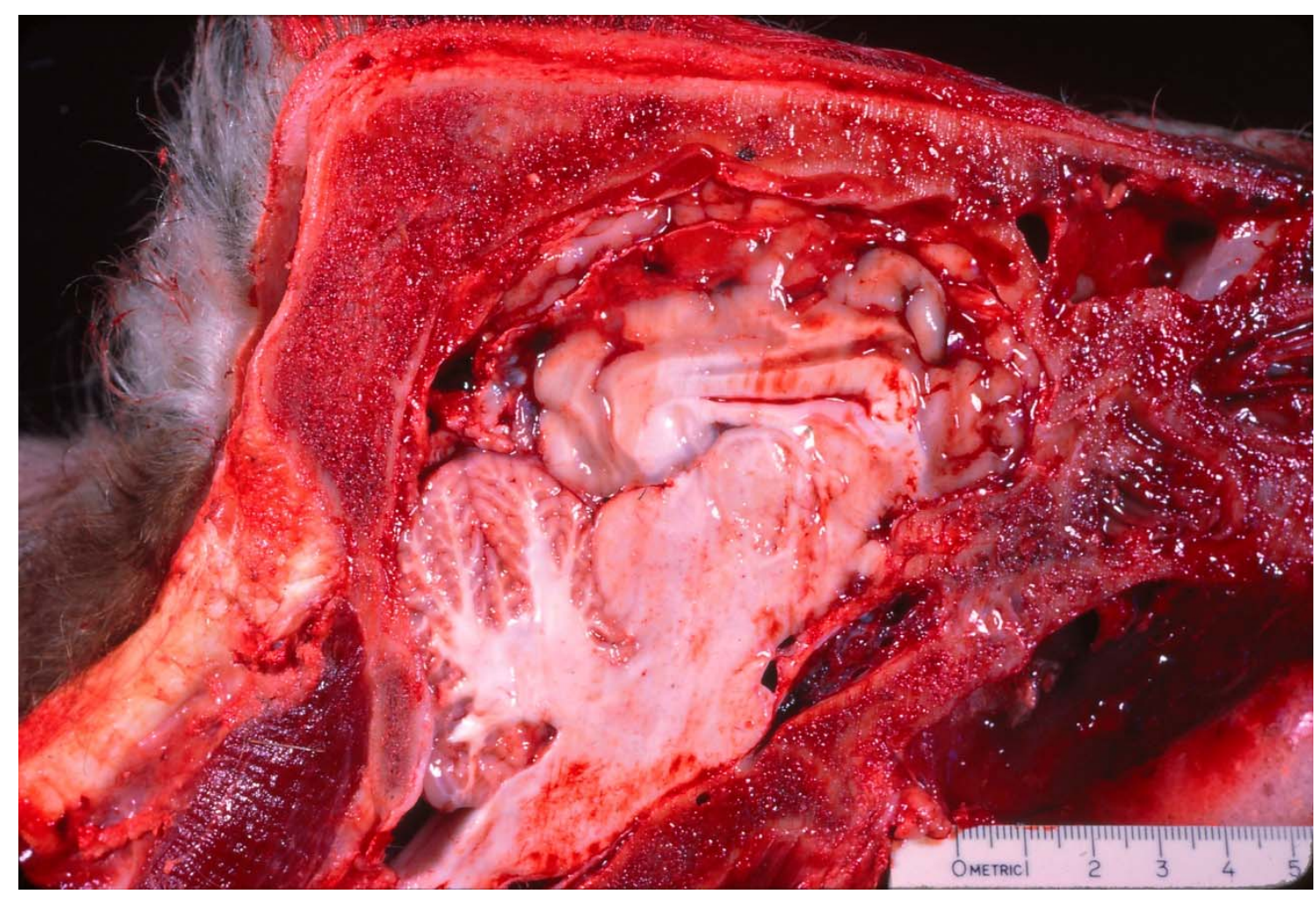

Fig. 18. Vitamin A deficiency in a neonatal calf with dorsoventral compression of the brain and rearward displacement of the cerebellum. 


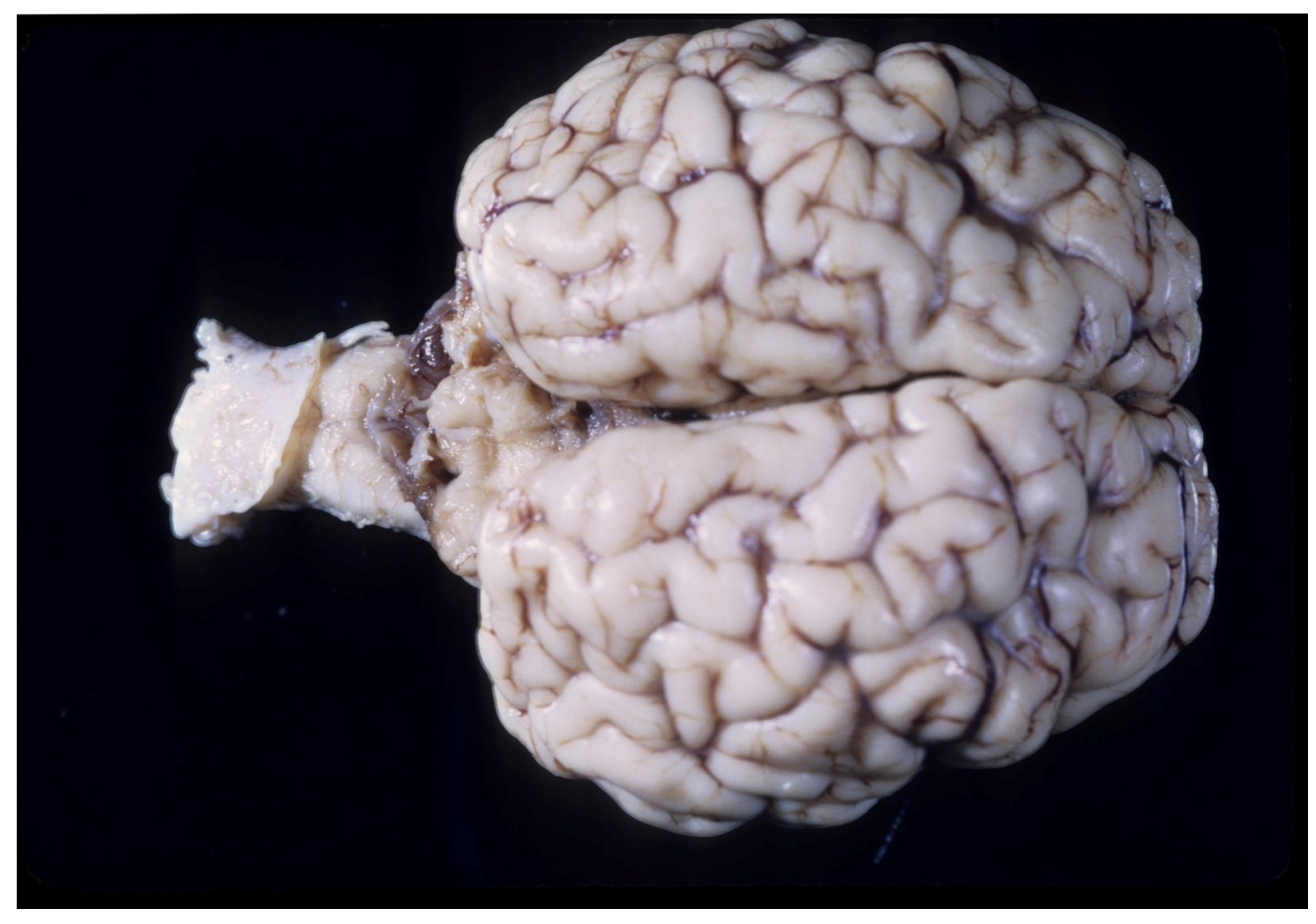

Fig. 19. Cerebellar hypoplasia in a calf infected in utero by bovine viral diarrhea virus. 


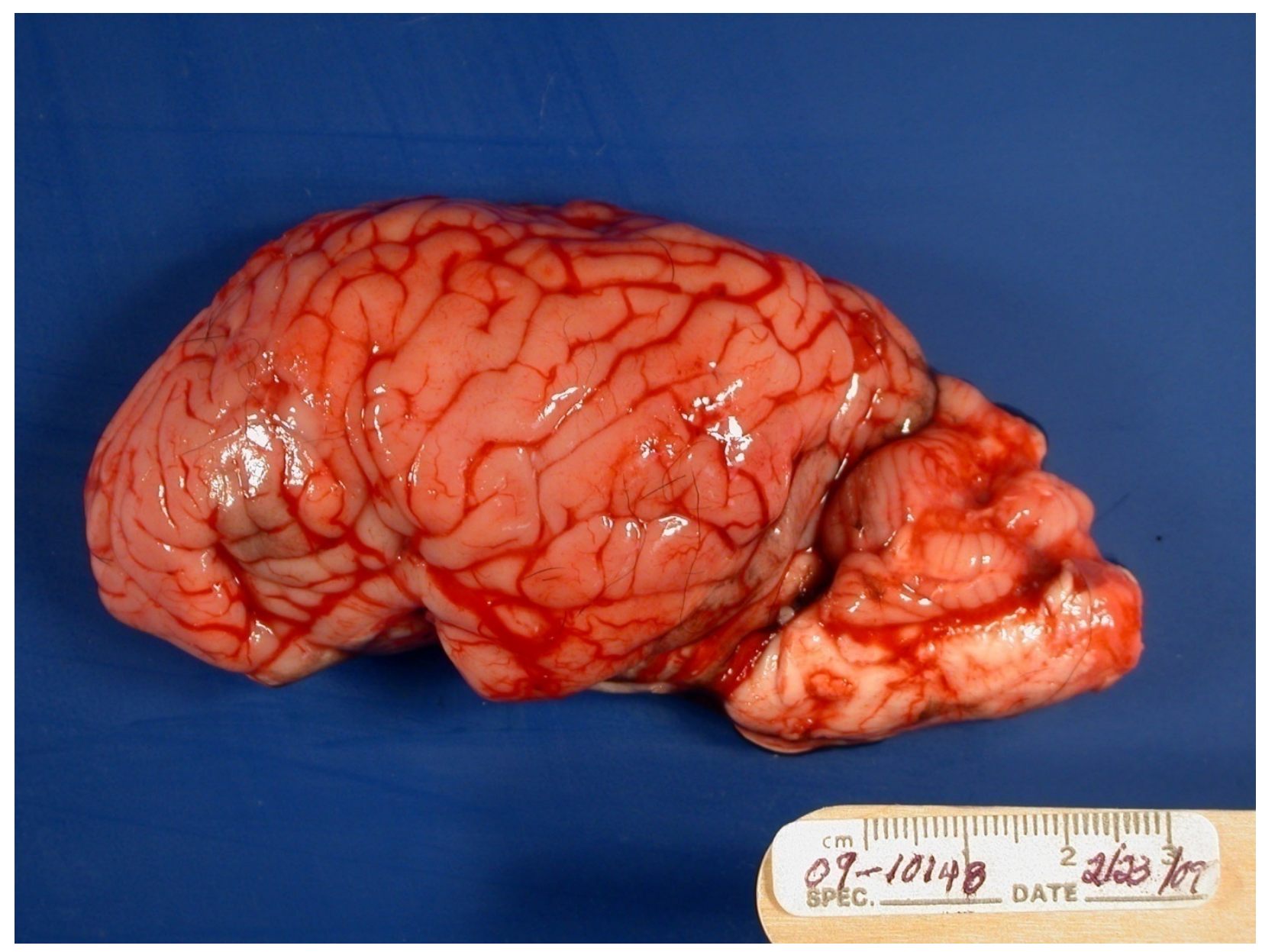

Fig. 20. Coning of the cerebellum of a calf brain due to edema and rearward displacement against the occipital bone. 


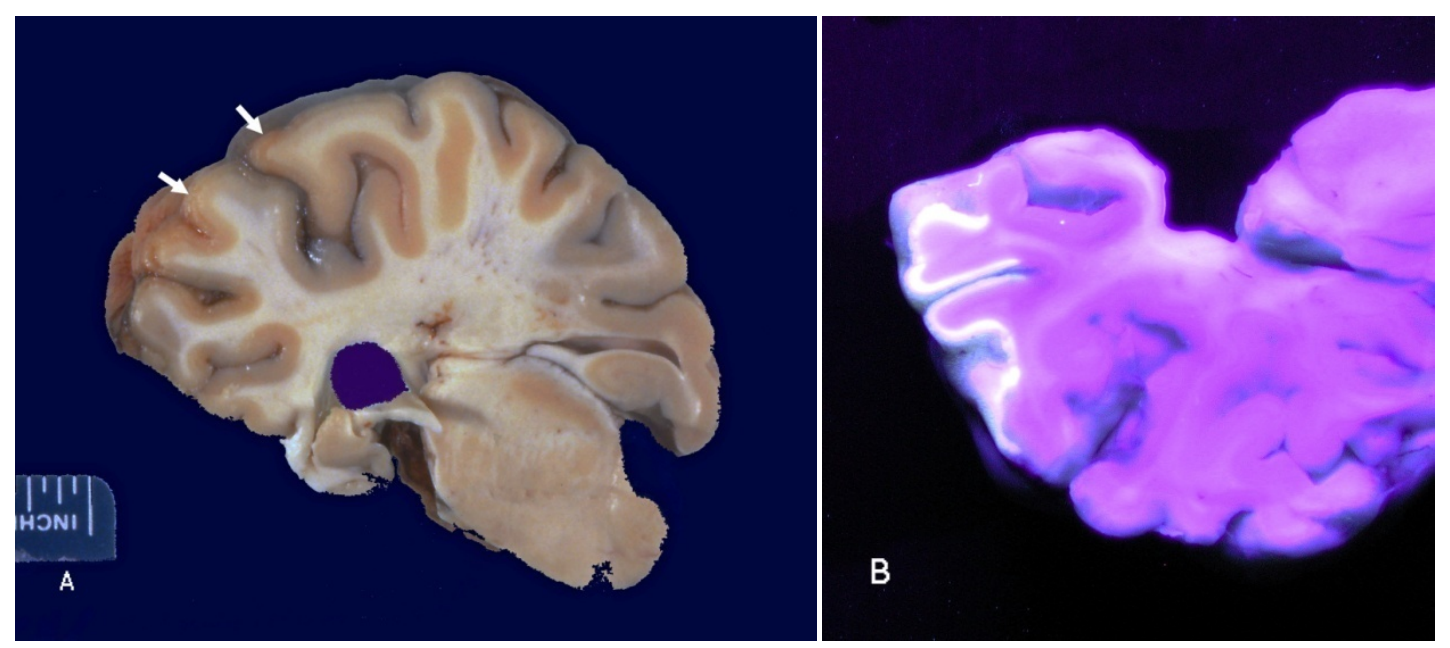

Fig. 21. Cross sections of cerebrum from calves with polioencephalomalacia. A. The areas of yellow-brown necrosis involving the outer grey lamina of the cortex (arrows) can be difficult to identify with certainty. B. Illumination with a black light makes the areas of laminar necrosis typical of the condition easily visible. 


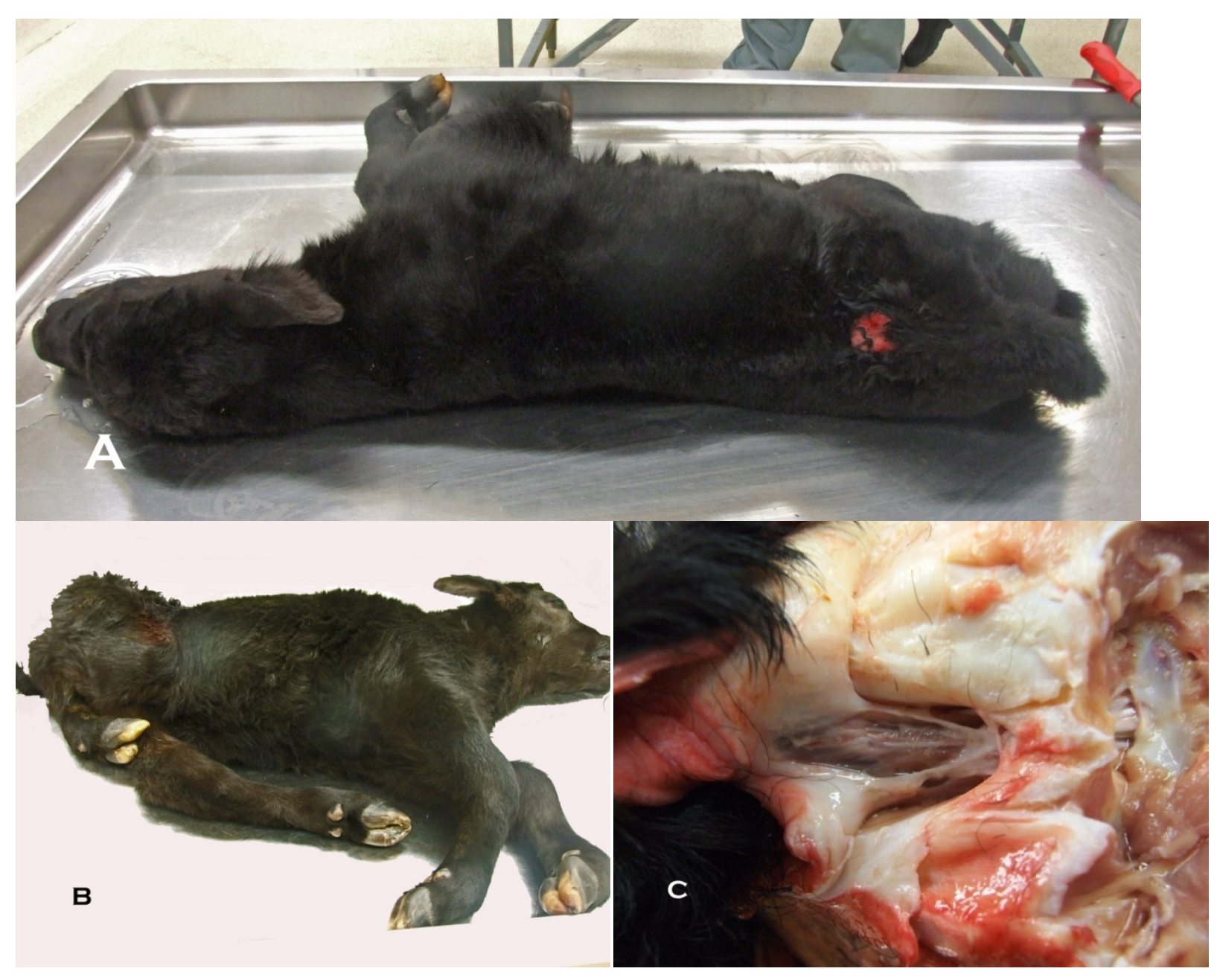

Fig. 22. Congenital spinal bifida and arthrogryposis in a crossbred calf. A. An open defect in the skin is present on the dorsal midline at the lumbosacral region. B. Arthrogryposis affecting all four limbs. C. The meningeal sac that protruded slightly through the skin and vertebral defect has been incised to expose the spinal cord. 


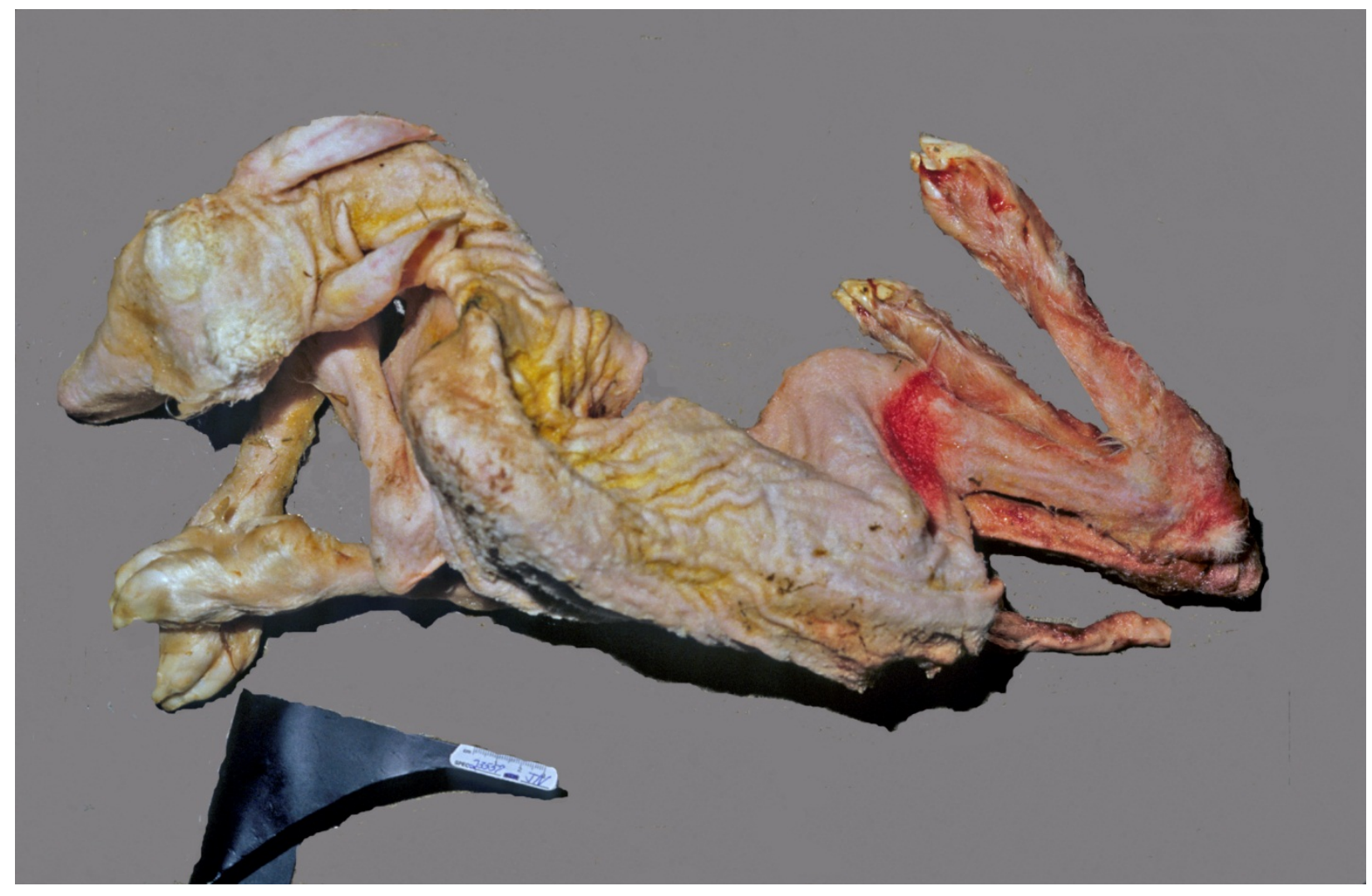

Fig. 23. Arthrogryposis, scoliosis, torticollis, and muscular hypoplasia in a newborn lamb infected in utero by Cache Valley virus. 